\title{
$\begin{array}{ll}\text { Research Square } & \text { Preprints are preliminary reports that have not undergone peer review. } \\ \text { They should not be considered conclusive, used to inform clinical practice, }\end{array}$ or referenced by the media as validated information. \\ Negative Potential Energy Content Analysis in Cracked Rotors Whirl Response
}

Mohammad AL-Shudeifat ( $\square$ mohd.shudeifat@ku.ac.ae)

Khalifa University of Science and Technology

\section{Fatima Alhammadi}

Khalifa University of Science and Technology

\section{Research Article}

Keywords: Cracked rotor system, open crack model, breathing crack model, negative stiffness, stability analysis

Posted Date: June 10th, 2021

DOl: https://doi.org/10.21203/rs.3.rs-579334/v1

License: (1) This work is licensed under a Creative Commons Attribution 4.0 International License. Read Full License

Version of Record: A version of this preprint was published at Scientific Reports on July 27th, 2021. See the published version at https://doi.org/10.1038/s41598-021-94836-8. 


\title{
Negative Potential Energy Content Analysis in Cracked Rotors Whirl Response
}

\author{
Mohammad A. AL-Shudeifat \\ Khalifa University of Science \& Technology \\ Abu Dhabi, PO BOX 127788 \\ mohd.shudeifat@ku.ac.ae
}

\author{
Fatima K. Alhammadi \\ Tawazun Technology \& innovation \\ Abu Dhabi , PO BOX 908 \\ fatima.alhammadi@tawazunti.ae
}

\begin{abstract}
Appearance of fatigue cracks in rotor systems mainly affects their stiffness content. The stability of such systems at steady-state running is usually analyzed by using the Floquet's theory. Accordingly, the instability zones of rotational speeds are dominated by negative stiffness content in the whirl response in the vicinity of critical rotational speeds. Consequently, an effective stiffness measure is introduced here to analyze the effect of the crack and the unbalance force vector orientation on the intensity of negative potential and stiffness content in the whirl response. The effective stiffness expression is obtained from the direct integration of the equations of motion of the considered cracked rotor system. The proposed effective stiffness measure is applied for steady-state and transient operations using the Jeffcott rotor model with open and breathing crack models. The intensity of negative potential and stiffness content in the numerical and experimental whirl responses is found to be critically depending on the propagation level of the crack and the unbalance force vector orientation. Therefore, this can be proposed as a crack detection tool in cracked rotor systems that either exhibit recurrent passage through the critical rotational speeds or steady-state running.
\end{abstract}

\section{Keywords}

Cracked rotor system, open crack model, breathing crack model, negative stiffness, stability analysis.

\section{Introduction}

Appearance of fatigue cracks in rotor systems significantly affects their whirl response dynamical behavior. Propagation of fatigue cracks could result in destructive whirl vibration amplitudes and rapid failure of rotor systems. Therefore, early detection of crack damages is critical for human safety and durability of rotor systems that are extensively applied in heavy-duty industrial applications.

Several types of crack damages have been addressed in the literature. However, two main types of cracks which are the transverse open and breathing crack models, have been extensively studied up-to-date. Most of the reported literature for transient and steady-state operations of rotor systems have been focused on the 
dynamical behavior of vibration whirl response in the vicinity of critical, subcritical and supercritical rotational speeds. The whirl dynamical behavior in the vicinity of critical and subcritical rotational speeds was investigated in [1] to differentiate between the whirl responses of these crack models in a cracked rotor system at steady-state operations. It was found that the forward subcritical whirl amplitudes were not observed in open crack model compared with breathing crack model. Several Vibration-Based Methods (VBMs) have been employed for crack damage detection. In [2-5], the VBMs were used for damage detection in rotor systems through whirl response analysis. In addition, VBMs have been applied to study the effect of crack damages on stiffness and damping properties in [6,7]. Analytical and numerical methods were applied to the equations of motion of a cracked rotor system in [8] to study the whirl response dynamical behavior.

In several studies, the transient whirl response during startup operations in which angular acceleration rate was considered in the equations of motion has been well-studied for cracked rotor systems with open and breathing crack models in [916]. In [9], experimental investigations have been conducted for analyzing the transient vibrational whirl behavior during the passage through the critical rotational speed. The transient whirl response was investigated to distinguish between the effect of the transverse and slant crack models in $[10,11]$ and between the responses of transverse crack and the shaft misalignment in rotor systems in [12]. Recently, a new backward whirl phenomena named as a post-resonance backward whirl has been captured in the transient response of accelerated cracked rotor systems immediately after the passage through the critical forward whirl speeds [13-15]. This post-resonance backward whirl was found to be associated with an abrupt reduction in whirl amplitudes in the vicinity of local minima of whirl amplitudes. The Hilbert-Huang Transform (HHT) which is a time frequency 
analysis method was employed in $[16,17]$ to study the transient vibration whirl response of rotors with transverse cracks.

In another series of publications, several models of cracked rotor systems were employed with several damage detection techniques for studying the vibration whirl signature of cracked rotor systems at steady-state running [18 - 25]. Modal analysis was used in [18] to detect the variations in natural frequencies, mode shapes, and the response to an applied forcing excitation in cracked rotors. Moreover, this method was used for investigating the effect of position and depth of the transverse crack on the modal properties of the considered systems. In [19, 20], a coupled radial, axial and torsional vibration whirl response was analyzed for crack detection and identification. In [21], a static rotor system with an open crack model in the shaft was considered for vibration whirl analysis to predict the transverse crack depth and its location. Different excitation kinds have been applied with rotor systems in [22-24] including multi-sine, parametric and mixed excitations. The multi-sine excitation method was used to evaluate the effect of the crack on nonlinear distortions in the whirl response of a cracked rotor system in [22]. The multiple scale method was applied to the equations of motion of rotors with active magnetic bearings in [23] and with both active magnetic bearings and time varying stiffness in [24] for stability analysis at steady-state solution. Moreover, an effective time-domain identification algorithm based on the Extended Kalman Filter (EKF) was employed in [25] for rotor damage detection where the neural networks accompanied with power spectral density characterization have been applied in [26] for crack damage identification.

The flexibility matrix and finite element methods were employed in determining the time-periodic stiffness matrix of cracked rotor systems in several publications such as in [1,7,9] and in [27-29]. In some other studies, the stability 
of the cracked rotor system was addressed. The Jeffcott rotor with a breathing crack model was considered in [30] and the FE model in [31] for determining the effect of the parametric excitation caused by the time-varying stiffness on the stability of cracked rotor systems. The unstable zones are usually obtained by applying the Floquet's theory to the free response of the parametrically excited cracked rotor system where the state-transition matrix is formulated using an identity matrix of initial conditions. The obtained unstable zones from the eigensolution of the statetransition matrix are associated with negative potential and stiffness energy content.

In recent series of publications, different methods and techniques have been applied for fault diagnostics in rotor systems. The autonomous ultrasonic testing method was employed in [32] for monitoring crack initiation and propagation by collecting the data of real-time whirl response using an ultrasonic wave system. In addition, signal processing methods were applied in $[33,34]$ to cracked rotors whirl response. Therefore, the auto-correlation and power spectral density functions were employed in [33] and the time-frequency info-grams method was employed in [34]. The robustness of both methods was also verified by experimental results. Furthermore, the non-linear output frequency response function (NOFRF) was used for damage diagnostics in rotor systems in $[35,36]$ where numerical simulation and experimental testing have been employed. In [35], the weighted rate-based (NOFRF) was applied with special index for rotor crack detection. This method was numerically and experimentally validated where the crack detection index has been observed to linearly proportional to the crack depth. However, further analysis was performed using the NOFRF in [36] to identify the crack depth and its location by using a crack position index (CPI) based on the higher harmonic response (HHR) and the dynamic compliance matrix. Another method based on fracture-mechanic principles has been applied in [37]. This method depends on the change in 
compliance matrix that induced by crack propagation in the shaft of steam turbine. Accordingly, the changes in natural bending, longitudinal, and torsional frequencies have been employed as an indication to cracks propagation. A different multiharmonic based technique was addressed in [38] for crack detection diagnostics where the multi-harmonics were found to be induced by crack propagation nonlinearities. An impedance-based structural health monitoring (ISHM) was studied in $[39,40]$. The detection of a crack propagation in rotating shafts was performed by employing the real-time impedance-based structural health monitoring method in [39]. This method is based on using piezoelectric transducers to perform a compact function of fault sensing and responsive signal actuation. In [40], the comparison results between the sensitivity matrices of single and double piezoelectric transducers was used as rotor damage indicator. The Discrete Wavelet Transform (DWT) method which is followed by auto-correlation process, was found to be effective for rotor damage detection in [41].

In the reviews of the state-of-the-art in [42-44], several crack detection methods and cracked rotor modeling techniques have been addressed where different kinds of cracked rotor models and several methods of whirl response analysis have been reviewed and discussed. The review performed in [42] has addressed the literature that focused on the effect of induced cracked-based nonlinearities on sub and super harmonics components in the whirl response. The use of variety of signalprocessing methods as tools for differentiating between crack-based nonlinearities from other kinds of nonlinearities in rotors was also addressed in that review. A list of most common methodologies of studying cracked rotors in various publications was provided and discussed in [43]. Therefore, the wavelet transform-based signal processing technique has been considered as one of optimal crack-based damage detection methods for the breathing crack model in rotors. In another review, the 
artificial intelligence-based rotor fault diagnostic (AI-RFD) was reviewed in [44] where the signal-processing based techniques were discussed and summarized.

In this study, an effective stiffness measure is introduced based on our prior study in [45] and applied to cracked rotor systems. Therefore, the impact of both open and breathing crack models at steady-state and transient running on the appearance of high negative potential and stiffness zones of rotational speeds is investigated. In addition, the influence of the unbalance force vector orientation on the negative potential content is considered in the numerical simulations and the experimental validations.

\section{Cracked Rotor Modeling}

The two-degree-of-freedom Jeffcott rotor model is considered here where it is represented by a concentric rigid disk of mass $m$ at the mid-span of simplysupported elastic massless shaft as shown in Figure 1. The equations of motion of the intact Jeffcott rotor model for the vector of horizontal and vertical whirl amplitudes $\mathbf{q}(t)=\left[\begin{array}{ll}u_{x}(t) & v_{y}(t)\end{array}\right]^{\mathrm{T}}$ and unbalance force excitation vector $\mathbf{F}_{u}(t)$ including the gravity effect are given in matrix form as

$$
\mathbf{M} q(t)+\mathbf{C} \&(t)+\mathbf{K q}(t)=\mathbf{F}_{u}(t)
$$

where $\mathbf{M}, \mathbf{C}$, and $\mathbf{K}$ are the mass, damping and stiffness matrices. The matrices $\mathbf{M}$

and $\mathbf{K}$, and the unbalance force vector $\mathbf{F}_{u}(t)$ for steady-state operation of intact Jeffcott rotor system are given, respectively, as

$$
\mathbf{M}=\left[\begin{array}{cc}
m & 0 \\
0 & m
\end{array}\right], \mathbf{K}=\frac{48 E}{L^{3}}\left[\begin{array}{cc}
I & 0 \\
0 & I
\end{array}\right] \text { and } \mathbf{F}_{u}(t)=\left[\begin{array}{c}
m e \Omega^{2} \cos (\Omega t) \\
m e \Omega^{2} \sin (\Omega t)-m g
\end{array}\right]
$$

where $m$ is the rigid disk mass, $L$ is the length of the shaft, $E$ is the modulus of elasticity of the shaft, $I$ is the area moment of inertia of the shaft cross-section, $\Omega$ 
is the shaft angular rotational speed and $e$ is the eccentricity of the unbalance force mass.

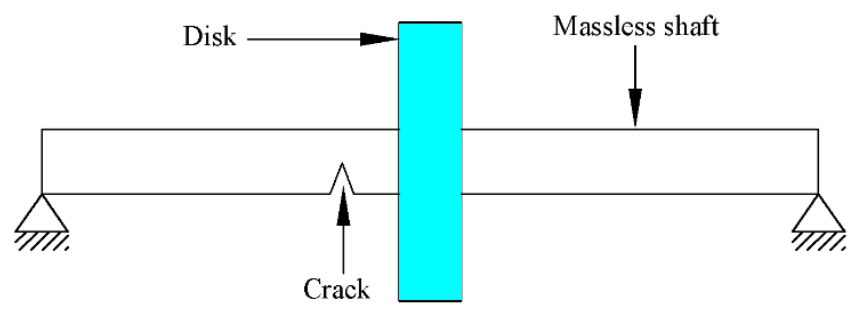

Figure 1 Jeffcott rotor with an open crack model.

The appearance of transverse crack in the shaft cross-sections is associated with time-varying stiffness matrix which is represented by $\mathbf{K}_{C}(t)$. Therefore, Eq. (1) can be rewritten for a cracked system as

$\mathbf{M} \&(t)+\mathbf{C} \&(t)+\mathbf{K}_{C}(t) \mathbf{q}(t)=\mathbf{F}_{u}(t)$

\subsection{Steady-State Operation}

Here we consider the open and breathing crack models for studying the potential energy content in a cracked Jeffcott rotor system at steady-state running.

\subsubsection{Open crack model}

The transverse open crack model is considered here as shown in Figure 2. The depth of the crack in the transverse radial direction is expressed by $h$. The crack opening orientation at the beginning of shaft's rotation is assumed to be at zero angle with respect to the fixed $X$ axis. The unbalance force vector orientation with respect to the crack opening direction is represented by the angle $\beta$ as shown. 

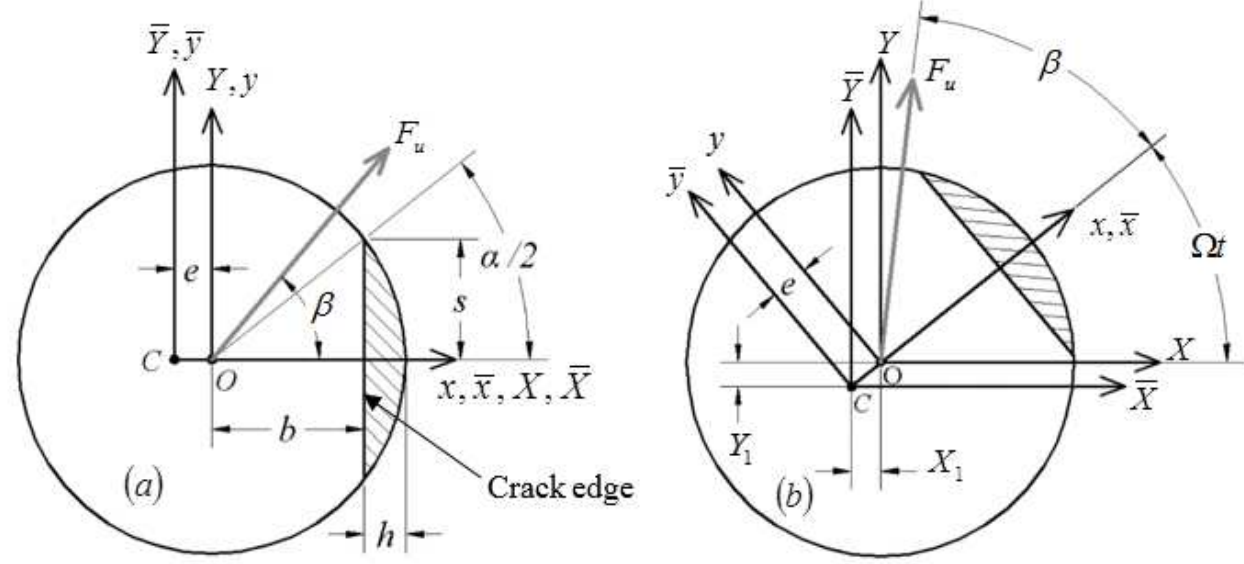

Figure 2 Schematic diagrams of the open crack in the shaft cross-section (a) before the shaft's rotation, and (b) after the shaft's rotation [13-15].

If the shaft has a transverse open crack as shown in Figure 2, the stiffness matrix in the rotating centroidal coordinates $\bar{x}$ and $\bar{y}$ axes is written as

$$
\mathbf{K}_{R}=\frac{48 E}{L^{3}}\left[\begin{array}{cc}
I_{\bar{y}} & 0 \\
0 & I_{\bar{x}}
\end{array}\right]
$$

where $I_{\bar{y}}=I_{y}-e^{2} A_{c e}$ and $I_{\bar{x}}=I_{x}$ are the area moments of inertia with respect to the centroidal rotating coordinates. The quantities $I_{x}, I_{y}, A_{c e}$ and $e$ are found for the normalized crack depth $\mu=h / R$ in $[1,13]$. The cracked element stiffness matrix $\mathbf{K}_{C}(t)$ with respect to the stationary coordinates is obtained by transforming $\mathbf{K}_{\mathrm{R}}$ via the following transformation

$$
\mathbf{K}_{C}(t)=\boldsymbol{\Psi} \mathbf{K}_{R} \boldsymbol{\Psi}^{\mathrm{T}}
$$

where $\boldsymbol{\Psi}$ is the coordinate transformation matrix which is expressed as

$$
\boldsymbol{\Psi}=\left[\begin{array}{cc}
\cos (\Omega t) & -\sin (\Omega t) \\
\sin (\Omega t) & \cos (\Omega t)
\end{array}\right]
$$

Accordingly, the resultant stiffness matrix $\mathbf{K}_{C}(t)$ in the stationary coordinates is obtained from Eq. (5) for the open crack model as

$$
\mathbf{K}_{C}(t)=\mathbf{K}_{1}+\mathbf{K}_{2} \cos (2 \Omega t)+\mathbf{K}_{3} \sin (2 \Omega t)
$$


where $\Omega$ is the constant angular rotational speed. For $\bar{I}_{1}=(1 / 2)\left(I_{\bar{x}}+I_{\bar{y}}\right)$ and $\bar{I}_{2}=(1 / 2)\left(I_{\bar{x}}-I_{\bar{y}}\right)$, the matrices $\mathbf{K}_{1}, \quad \mathbf{K}_{2}$ and $\mathbf{K}_{3}$ are obtained from the transformation as

$$
\mathbf{K}_{1}=\frac{48 E}{L^{3}}\left[\begin{array}{cc}
\bar{I}_{1} & 0 \\
0 & \bar{I}_{1}
\end{array}\right], \mathbf{K}_{2}=\frac{48 E}{L^{3}}\left[\begin{array}{cc}
-\bar{I}_{2} & 0 \\
0 & \bar{I}_{2}
\end{array}\right] \text {, and } \mathbf{K}_{3}=\frac{48 E}{L^{3}}\left[\begin{array}{cc}
0 & -\bar{I}_{2} \\
-\bar{I}_{2} & 0
\end{array}\right]
$$

\subsubsection{Breathing crack model}

The breathing crack model in $[15,30]$ is also considered here to obtain the timevarying stiffness matrix $\mathbf{K}_{C}(t)$. Therefore, the instantaneous time-varying moments of area in the cracked cross-section are firstly calculated based on the shaft angle of rotation $\theta(t)=\Omega t$ at each time step in the numerical integration as

$$
\begin{aligned}
& I_{\bar{X}}(t)=I-\left(I-\bar{I}_{1}\right) f_{1}(t) \\
& I_{\bar{Y}}(t)=I+\left(I-\bar{I}_{1}\right) f_{1}(t)-\left(2 I-\bar{I}_{1}-\bar{I}_{2}\right) f_{2}(t) \\
& I_{\bar{X} \bar{Y}}(t)=\left(-\frac{\bar{I}_{1}-\bar{I}_{2}}{2}+\frac{A_{1} e^{2}}{2}\right) \sin (2 \theta(t)) \sum_{k=1}^{p} \frac{2 \bar{\theta}_{2} \sin \left(\pi-k \bar{\theta}_{2}\right)}{\pi^{2}-k^{2} \bar{\theta}_{2}^{2}} \sin (k \theta(t))
\end{aligned}
$$

where $f_{1}(t)$ and $f_{2}(t)$ are the crack breathing functions which are given as

$$
\begin{aligned}
& f_{1}(t)=\cos ^{n}\left(\frac{\theta(t)}{2}\right)=\frac{1}{2^{n}}\left[\left(\begin{array}{c}
n \\
n / 2
\end{array}\right)+2 \sum_{j=0}^{(n / 2)-1}\left(\begin{array}{c}
n \\
j
\end{array}\right) \cos \left((n-2 j) \frac{\theta(t)}{2}\right)\right] \\
& f_{2}(t)=\frac{1}{\pi}\left[\frac{\theta_{1}+\theta_{2}}{2}-\frac{2}{\left(\theta_{2}-\theta_{1}\right)} \sum_{i=1}^{p} \frac{\cos \left(i \theta_{2}\right)-\cos \left(i \theta_{1}\right)}{i^{2}} \cos (i \theta(t))\right]
\end{aligned}
$$

where $\theta_{1}$ is the angles at which the crack starts to close and $\theta_{2}$ is the angle at which the crack becomes fully close. The formulas of $\theta_{1}, \theta_{2}, I, \bar{I}_{1}, \bar{I}_{2}, A_{1}$ and $e$ are found in $[15,30]$. Accordingly, the cracked shaft stiffness matrix $\mathbf{K}_{C}(t)$ in the fixed centroidal coordinates for a breathing crack model is now expressed as 


$$
\mathbf{K}_{C}(t)=\left[\begin{array}{cc}
K_{\bar{Y}}(t) & K_{\bar{X} \bar{Y}}(t) \\
K_{\bar{X} \bar{Y}}(t) & K_{\bar{X}}(t)
\end{array}\right]=\frac{48 E}{L^{3}}\left[\begin{array}{cc}
I_{\bar{Y}}(t) & I_{\bar{X} \bar{Y}}(t) \\
I_{\bar{X} \bar{Y}}(t) & I_{\bar{X}}(t)
\end{array}\right]
$$

\subsection{Transient Operation}

\subsubsection{Open crack model}

For transient operation, the angular acceleration rate during the shaft rotation significantly alters the system's mathematical model. The internal material damping is also considered according to [46] to be proportional to the stiffness matrix $\mathbf{K}_{R}$ in Eq. (4) of the cracked shaft. Accordingly, this damping content is expressed as $\mathbf{D}_{R}=\zeta \mathbf{K}_{R}$ where $\zeta$ is the internal viscous damping coefficient. Therefore, the internal damping matrix $\mathbf{D}_{R}$ is transformed into the fixed coordinates using the transformation matrix $\boldsymbol{\Psi}$ which was previously given in Eq. (6) to obtain the damping force in the fixed coordinates as $\mathbf{F}_{D}=-\zeta\left(\mathbf{K}_{R} \&(t)+\mathbf{K}_{c i r} \mathbf{q}(t)\right)$ where $\mathbf{K}_{c i r}$ is the skew-symmetric circulation matrix. Accordingly, for the angle of rotation $\theta(t)=0.5 \alpha t^{2}$ and angular speed $\Omega(t)=\alpha t$ at the angular acceleration rate $\alpha$, the stiffness matrix $\mathbf{K}_{C}(t)$ in Eq. (3) of the cracked shaft with an open crack model and the damping matrix $\mathbf{C}$ for transient rotation are expressed as

$$
\begin{aligned}
& \mathbf{K}_{C}(t)=\mathbf{K}_{1}+\mathbf{K}_{2} \cos (2 \theta(t))+\mathbf{K}_{3} \sin (2 \theta(t))+\Omega(t) \zeta \mathbf{K}_{c i r} \\
& \mathbf{C}=\gamma \mathbf{M}+\zeta \mathbf{K}_{R}
\end{aligned}
$$

where $\gamma$ is the external viscous damping coefficient which is selected to be $\gamma=100 \mathrm{~s}^{-1}$ according to [46]. In addition, $\zeta$ was usually assumed of order $O\left(10^{-7}\right)$ for steel shafts in the literature $[47,48]$. Therefore, $\zeta$ is selected for the numerical simulation as $\zeta=2 \times 10^{-7} \mathrm{~s}$. 


\subsubsection{Breathing crack models}

Considering the breathing crack model, the stiffness matrix $\mathbf{K}_{C}(t)$ of the cracked shaft is still obtained according to Eqs. (9-11) at $\theta(t)=0.5 \alpha t^{2}$ and $\Omega(t)=\alpha t$. Moreover, the term including the circulation matrix in Eq. (12) should be also maintained in the total stiffness of the cracked shaft with breathing crack model where the total stiffness becomes $\mathbf{K}_{C}(t)+\Omega(t) \zeta \mathbf{K}_{c i r}$ rather than $\mathbf{K}_{C}(t)$ in Eq. (3).

During transient operations, the angular acceleration rate $\alpha$ is also affecting the unbalance force vector components for both open and breathing crack models. Accordingly, by incorporating the angular acceleration rate and the unbalance force vector angle $\beta$ of the cracked shaft, the unbalance force vector $\mathbf{F}_{u}(t)$ including the gravity effect at $\theta(t)=0.5 \alpha t^{2}$ and $\Omega(t)=\alpha t$ is written as

$$
\mathbf{F}_{u}(t)=\left[\begin{array}{c}
m e \alpha^{2} t^{2} \cos \left(\alpha t^{2} / 2+\beta\right)+m e \alpha \sin \left(\alpha t^{2} / 2+\beta\right) \\
m e \alpha^{2} t^{2} \sin \left(\alpha t^{2} / 2+\beta\right)-m e \alpha \cos \left(\alpha t^{2} / 2+\beta\right)-m g
\end{array}\right]
$$

\section{Effective Stiffness Calculations}

Here, an effective stiffness measure for the considered cracked Jeffcott rotor system at steady-state and transient operations is introduced based on [45]. By premultiplying the equations of motion in Eq. (3) by of and integrating for zero initial condition from $t=0$ to the steady-state time of operation $t_{s s}$, we obtain

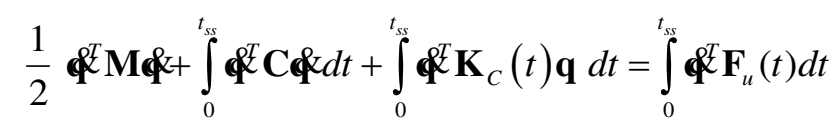

Therefore, from this equation we obtain the following representation of the total potential energy in the cracked rotor system as 


$$
P(t)=\int_{0}^{t} \boldsymbol{\phi}^{P} \mathbf{K}_{C}(t) \mathbf{q} d t
$$

This potential energy in Eq. (13) can be written in the following equivalent form as

$$
P(t)=\frac{1}{2} k_{e f f}(t) z(t)^{2}
$$

where $z(t)$ is the whirl amplitude which is obtained from $z(t)=\sqrt{u_{x}(t)^{2}+v_{y}(t)^{2}}$. Accordingly, the effective stiffness content is obtained as

$$
k_{e f f}(t)=\frac{2 P(t)}{z(t)^{2}}
$$

\section{Numerical Simulation and Experimental Results}

The physical parameters in Table 1 of the Spectra Quest MFS-RDS experimental rotordynamic simulator shown in Figure 3 are employed in the numerical simulation to obtain the potential energy and effective stiffness measures based on Eqs. (15) and (17). The experimental rotordynamic simulator incorporates a single disk at the mid-span of the shaft as shown. Two proximity probes were installed to collect the experimental data of horizontal and vertical whirl amplitudes of the system. These whirl amplitudes form the vector of displacements $\mathbf{q}=\left[\begin{array}{ll}u_{x} & v_{y}\end{array}\right]^{\mathrm{T}}$ which is employed with Eqs. (15) and (17) to obtain the experimental potential energy and effective stiffness values. The resonance frequency of the experimental configuration is obtained for the intact case to be $\Omega_{\exp } \cong 57 \mathrm{~Hz}$ where the obtained one from the theoretical Jeffcott rotor model is $\Omega_{J F} \cong 55.7 \mathrm{~Hz}$.

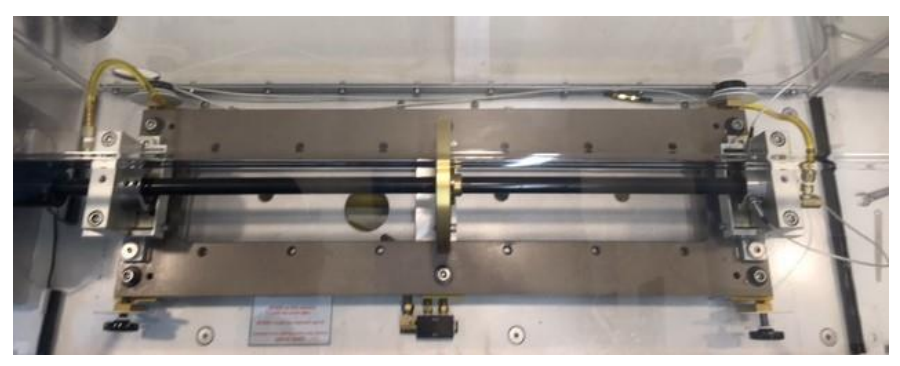

Figure 3 Spectra Quest MFS-RDS rotordynamic simulator 
Table 1 Physical parameters of the rotor

\begin{tabular}{|l|l|}
\hline Description & Value \\
\hline Length of the rotor, $L$ & $700 \mathrm{~mm}$ \\
\hline Radius of the rotor, $R$ & $10 \mathrm{~mm}$ \\
\hline Density of rotor, $\rho$ & $7850 \mathrm{~kg} / \mathrm{m}^{3}$ \\
\hline Modulus of elasticity, $E$ & $2.1 \times 10^{11} \mathrm{~N} / \mathrm{m}^{2}$ \\
\hline$m \cdot e$ & $1 \times 10^{-4} \mathrm{~kg} \cdot \mathrm{m}$ \\
\hline$\beta$ & varying \\
\hline$\gamma$ & $100 \mathrm{~s}^{-1}$ \\
\hline$\zeta$ & $2 \times 10^{-7} \mathrm{~s}$ \\
\hline
\end{tabular}

\subsection{Steady-State Response}

The response of the cracked rotor system for steady-state operations is obtained from the numerical integration of Eq. (3) according to the given physical parameters in Table 1 of the considered cracked system. Therefore, the numerical and experimental whirl amplitudes are obtained for open and breathing crack models. Accordingly, Eqs. (15) and (17) are employed with the numerical and experimental whirl responses for calculating the potential energy and effective stiffness values.

\subsubsection{Open crack model}

The unstable zones of shaft rotational speeds are usually dominated by negative potential and negative stiffness content. The positive potential energy values are set to zero in all contour plots in the paper to distinguish the negative potential energy zones. In addition, the blue dotted line in all contour plots represents the resonance forward whirl rotational speeds. Therefore, the effect of crack propagation on negative potential and effective stiffness during shaft operation at steady-state response is shown in Figures 4 and 5 for different unbalance force vector orientations of gravity-free vertical rotor system. It was observed that the crack 
depth and unbalance force vector angles have significant impact on the extent and intensity of the negative potential energy zones. Extended zones of negative potential for wide range of rotational speeds are observed when the unbalance force angle is between $\beta=\pi / 2$ and $\beta=\pi$ as shown in Figure 5. Therefore, this zone of unbalance force vector angles significantly affects the stability of the cracked system and elevates the severity of crack propagation. Furthermore, it is also observed that at $\beta=\pi / 6$ and $\beta=\pi / 3$ in Figure 4 and $\beta=7 \pi / 6$ in Figure 5 , the negative potential content has the highest levels at $\mu \geq 0.25$.
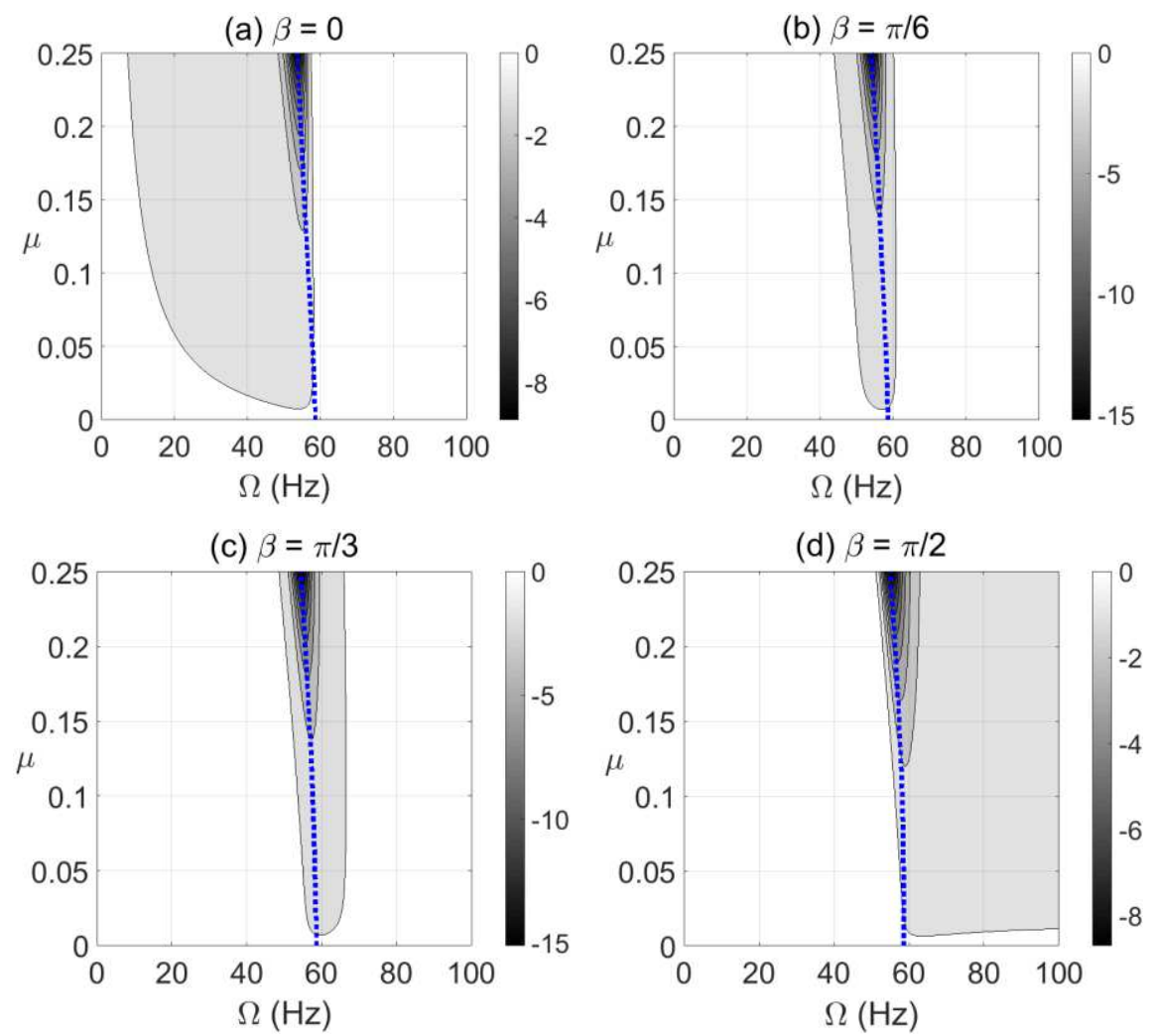

Figure 4 Effect of the open crack model depth $\mu$ at varying shaft rotational speeds on the potential energy content in steady-state response at unbalance force angles $\beta=0$ in (a), $\beta=\pi / 6 \mathrm{rad}$ in (b), $\beta=\pi / 3 \mathrm{rad}$ in (c) and $\beta=\pi / 2 \mathrm{rad}$ in (d). 

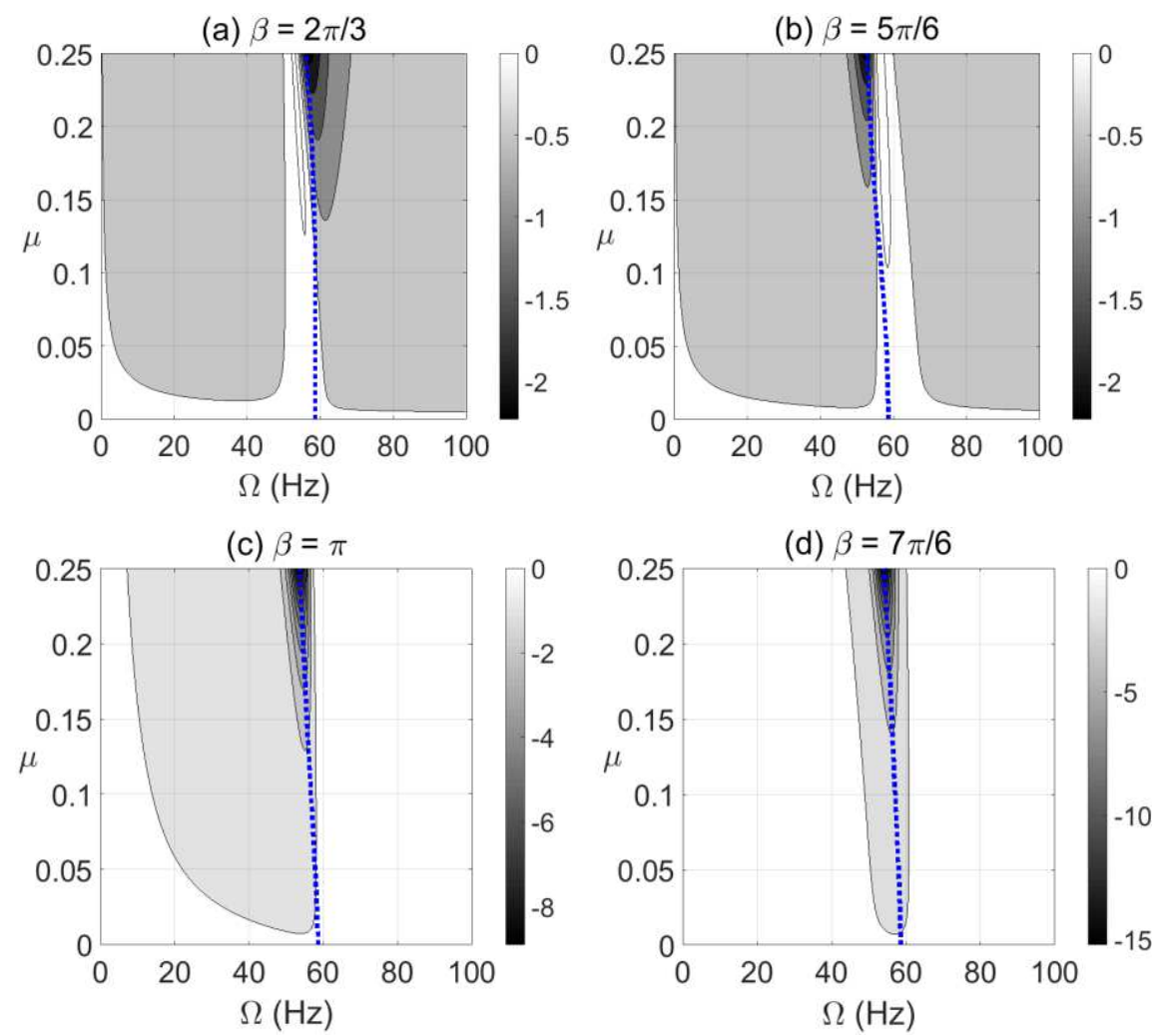

Figure 5 Effect of the open crack model depth $\mu$ at varying shaft rotational speeds on the potential energy content in steady-state response at unbalance force angles $\beta=2 \pi / 3 \mathrm{rad}$ in (a), $\beta=5 \pi / 6 \mathrm{rad}$ in (b), $\beta=\pi \mathrm{rad}$ in (c) and $\beta=7 \pi / 6 \mathrm{rad}$ in (d).

To clearly identify the effect of $\beta$ on the level of negative potential rather than the ranges of its extent, the results are obtained and plotted in Figure 6 for vertical shaft and in Figure 7 for horizontal shaft configurations at different crack depths and various values of $\beta$ and shaft's rotational speeds. It is observed in these figures that the zones of $\beta$ values of high levels of negative potential and stiffness are nearly centered at $\beta=\pi / 4$. Therefore, near to this angle the crack propagation has the highest effect on the stability of the cracked system than other angles. It is also observed that the gravity has less impact on the negative potential energy content than other parameters as observed in Figure 6 of vertical system and Figure 7 of horizontal system. 
(a) $\mu=0.05$

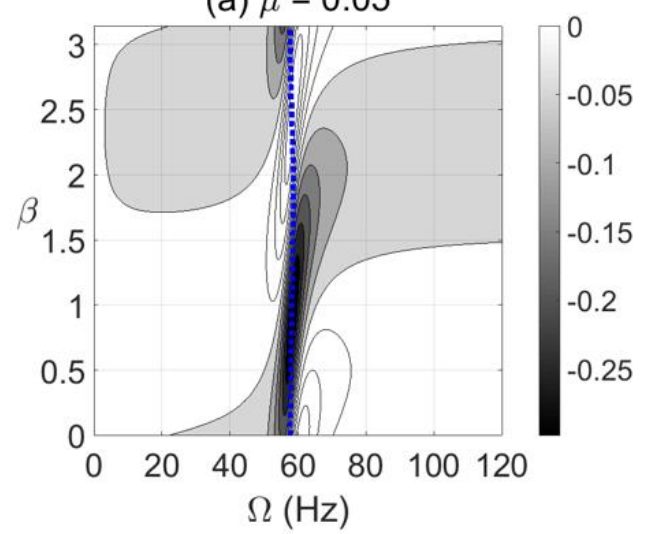

(c) $\mu=0.15$

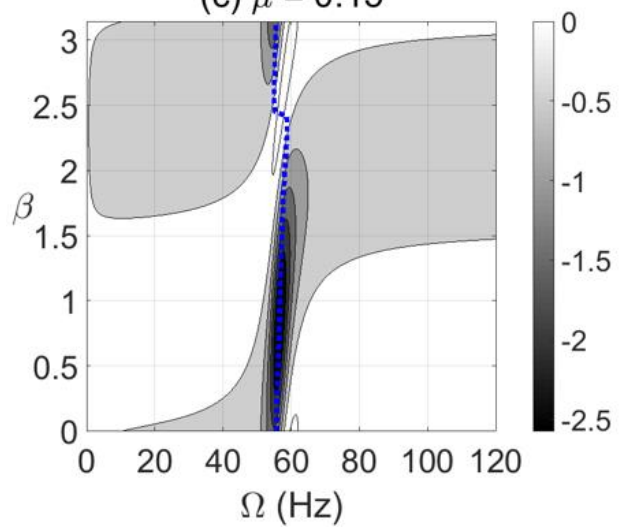

(b) $\mu=0.1$

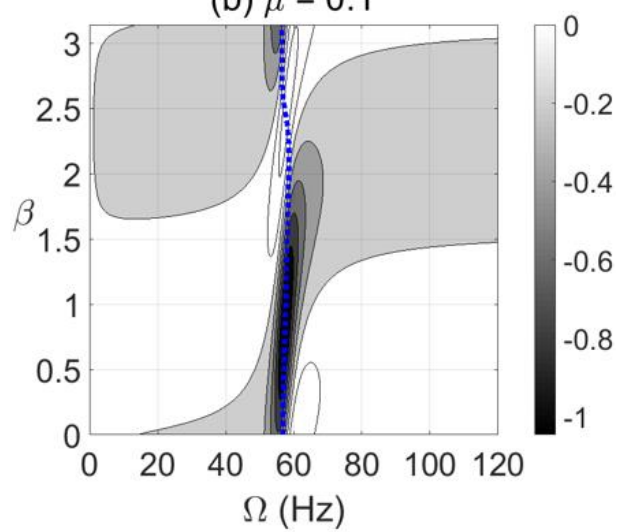

(d) $\mu=0.2$

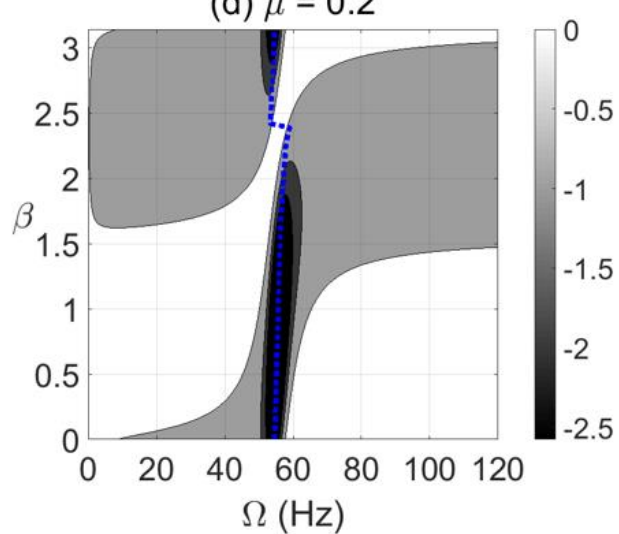

Figure 6 Effect of unbalance force vector angle $\beta$ at varying shaft rotational speeds on potential energy content in steady-state response of vertical cracked rotor system with open crack model depths $\mu=0.05$ in (a), $\mu=0.1$ in (b), $\mu=0.15$ in (c) and $\mu=0.2$ in (d). 
(a) $\mu=0.05$

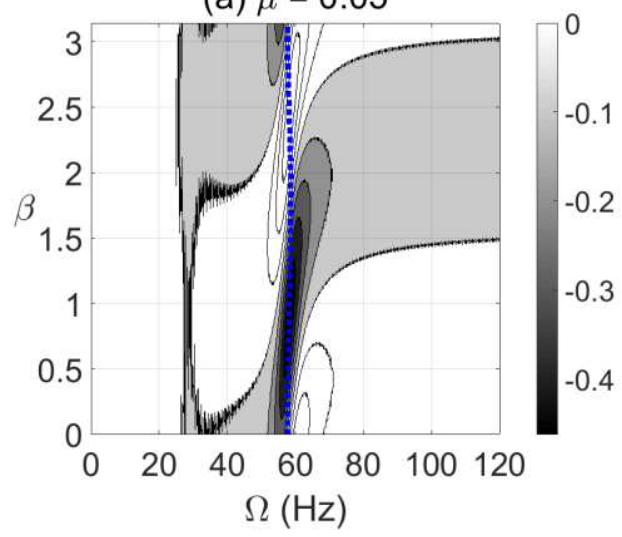

(c) $\mu=0.15$

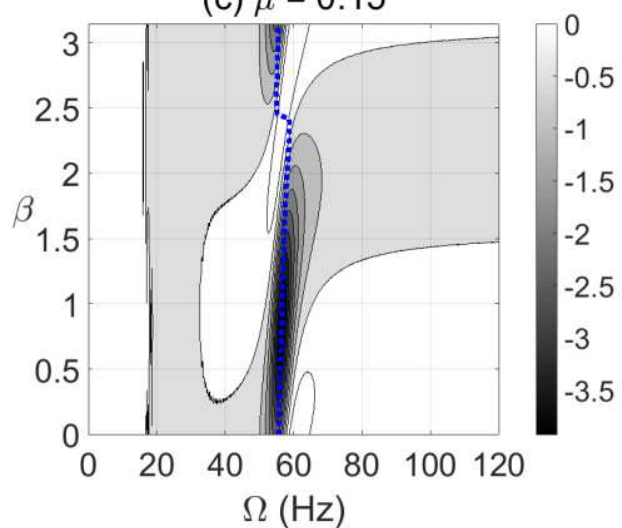

(b) $\mu=0.1$

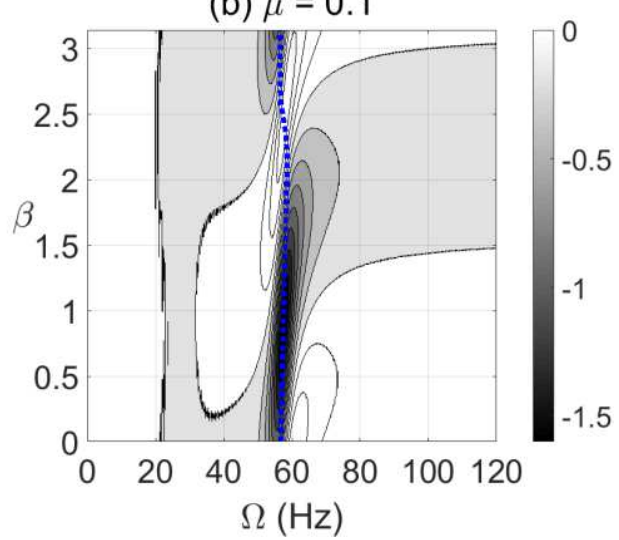

(d) $\mu=0.2$

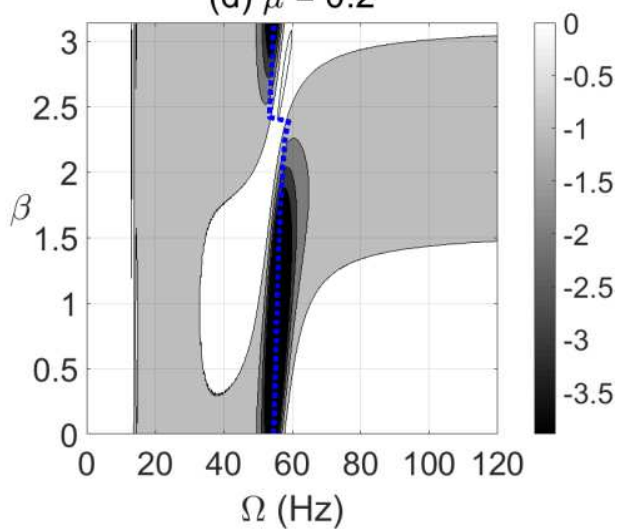

Figure 7 Effect of unbalance force vector angle $\beta$ at varying shaft rotational speeds on potential energy content in steady-state response of horizontal cracked rotor system with open crack model depths $\mu=0.05$ in (a), $\mu=0.1$ in (b), $\mu=0.15$ in (c) and $\mu=0.2$ in (d).

\subsubsection{Breathing crack model}

The effect of breathing crack model on negative potential energy and effective stiffness zones of the horizontal cracked rotor system for different crack depths, varying unbalance force vector angles and varying steady-state rotational speeds is shown in Figure 8. Two major zones of negative potential and stiffness are observed at each crack depth where one of them appear in the pre-resonance zone at high values of $\beta$ and the other one appears in the post-resonance zone at low values of $\beta$. In addition other extended zones start to appear in the vicinity of $1 / 3,1 / 2$ and $2 / 3$ of the resonance whirl rotational speed as shown. The intensity and recurrence of these zones are affected by the crack depth as shown. At $\mu=0.2$, the level of negative potential energy and stiffness gets very high as shown from the gray-scale colored bar, especially in the neighborhood of the resonance rotational whirl speed. 
In addition, at resonance whirl rotational speed, the negative potential energy content is observed to be dominant. Both crack open and breathing crack models in Figures 7 and 8 are associated with significant negative potential energy zones that appear at pre- and post-resonance rotational speeds. These zones are strongly affected by the crack depth and the unbalance force vector orientation.

(a) $\mu=0.05$

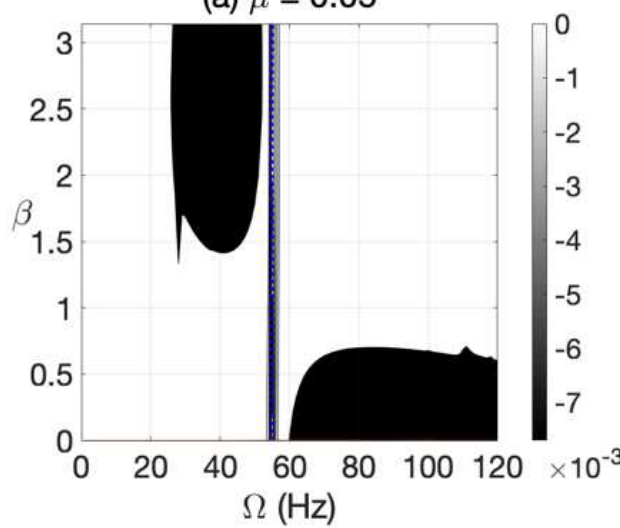

(c) $\mu=0.15$

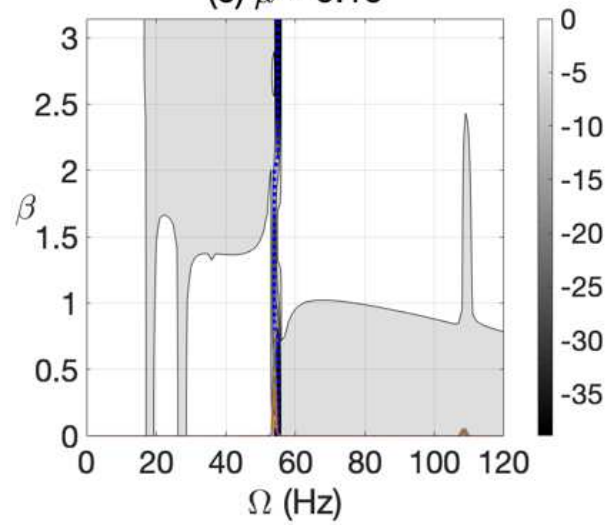

(b) $\mu=0.1$

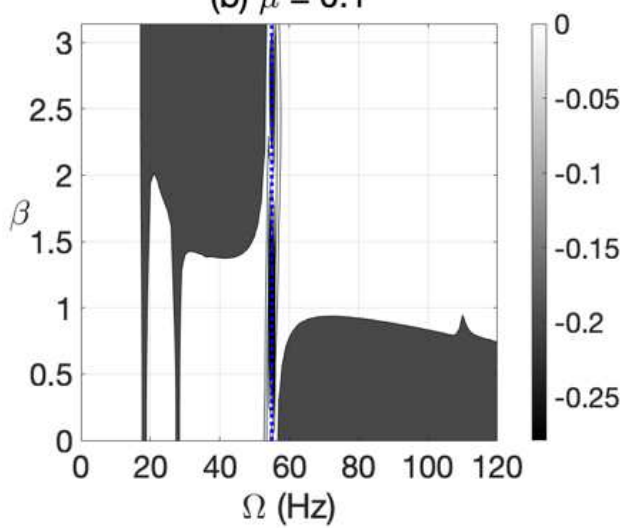

(d) $\mu=0.2$

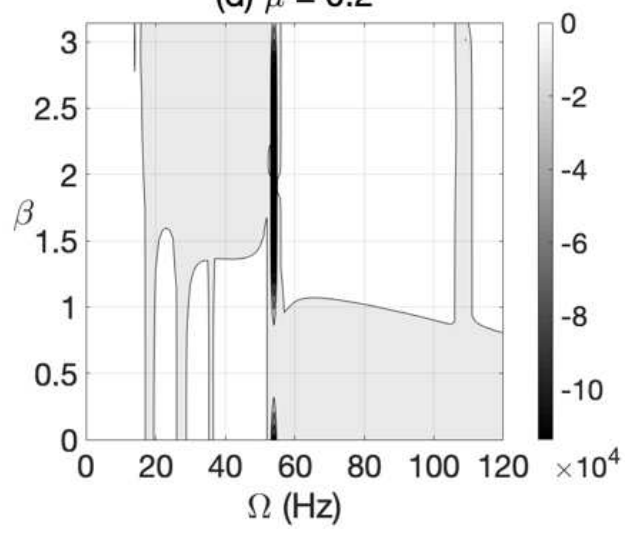

Figure 8 Effect of unbalance force vector angle $\beta$ at varying shaft rotational speeds on potential energy content in steady-state response of horizontal cracked rotor system with breathing crack model depths $\mu=0.05$ in (a), $\mu=0.1$ in (b), $\mu=0.15$ in (c) and $\mu=0.2$ in (d).

\subsubsection{Experimental results}

The changes in experimental whirl amplitudes with respect to the shaft rotational speed are plotted in Figure 9 for crack depth $\mu=0.2$ at two different unbalance force vector angles $\beta=4 \pi / 9(1.4 \mathrm{rad})$ and $\beta=8 \pi / 9(2.8 \mathrm{rad})$. The resonance rotational speed is obtained from this figure for $\beta=4 \pi / 9 \mathrm{rad}$ and $\beta=4 \pi / 9 \mathrm{rad}$ at $\mu=0.2$ to be $\Omega_{\mathrm{exp}} \cong 54.5 \mathrm{~Hz}$ where the numerical simulation one 
is $\Omega_{\text {num }} \cong 57 \mathrm{~Hz}$. The obtained potential energy and the corresponding effective stiffness values based on the experimental whirl amplitudes and Eqs. (15) and (17) are plotted in Figure (10) for $\beta=1.4 \mathrm{rad}$ and in Figure (11) for $\beta=2.8 \mathrm{rad}$. It is observed in these figures that in the vicinity of the critical rotational speed $\Omega_{\text {exp }} \cong 54.5 \mathrm{~Hz}$ significant transitions between positive and negative effective stiffness values take place with various intensities. These observations are in good agreement with the numerical simulation prediction in Figure $7 \mathrm{~d}$ for both considered unbalance force angles.
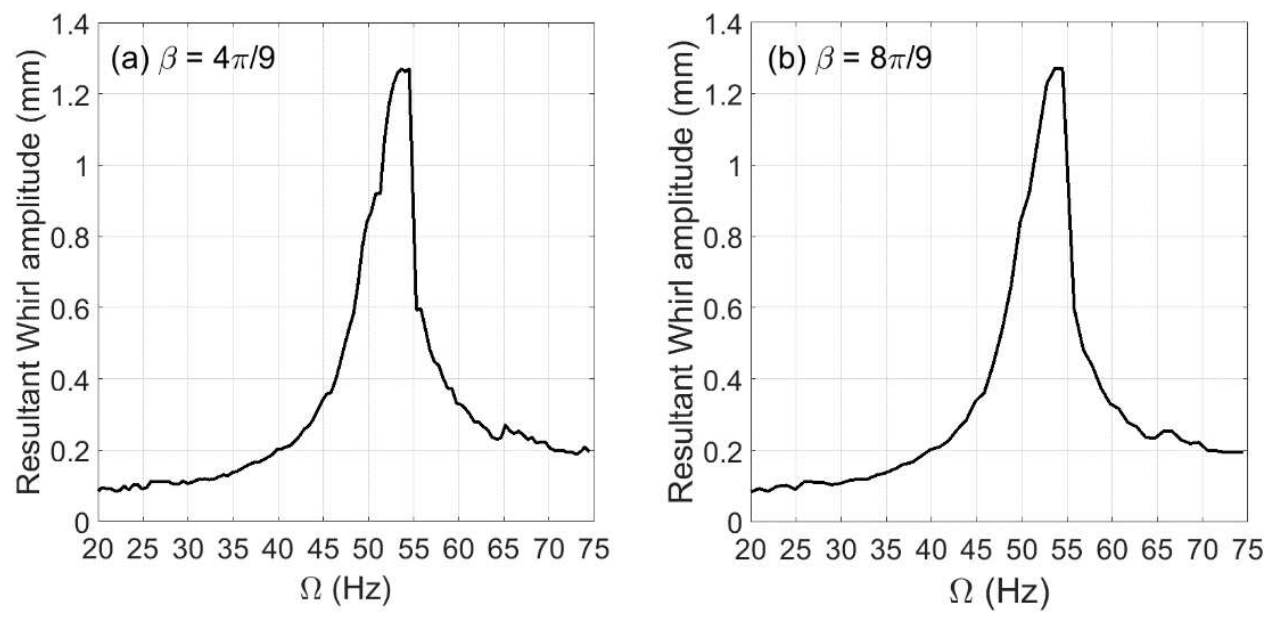

Figure 9 Experimental whirl amplitudes in steady-state response versus the shaft rotational speeds at $\mu=0.2$ and $\beta=4 \pi / 9 \mathrm{rad}$ in (a) and $\beta=8 \pi / 9 \mathrm{rad}$ in (b) of the horizontal cracked rotor system.
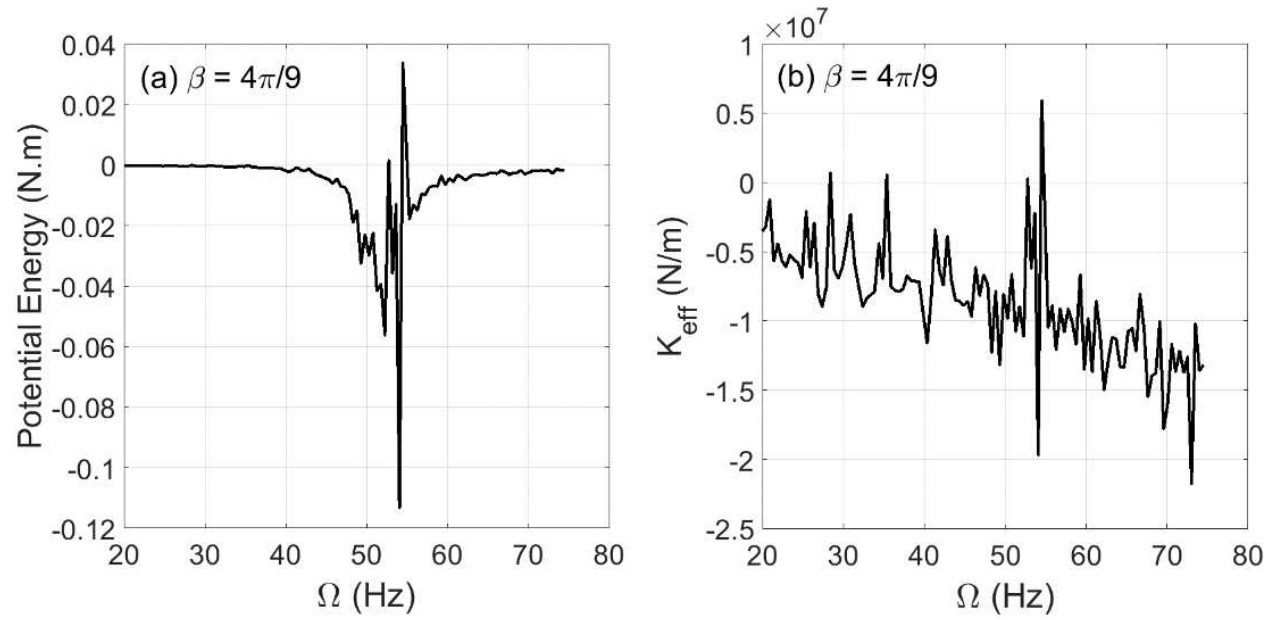

Figure 10 Experimental results in steady-state response of potential energy content in (a) and the corresponding effective stiffness content in (b) for varying shaft rotational speeds at $\mu=0.2$ and $\alpha=25 \mathrm{rad} / \mathrm{s}^{2}$ of the horizontal cracked rotor system. 

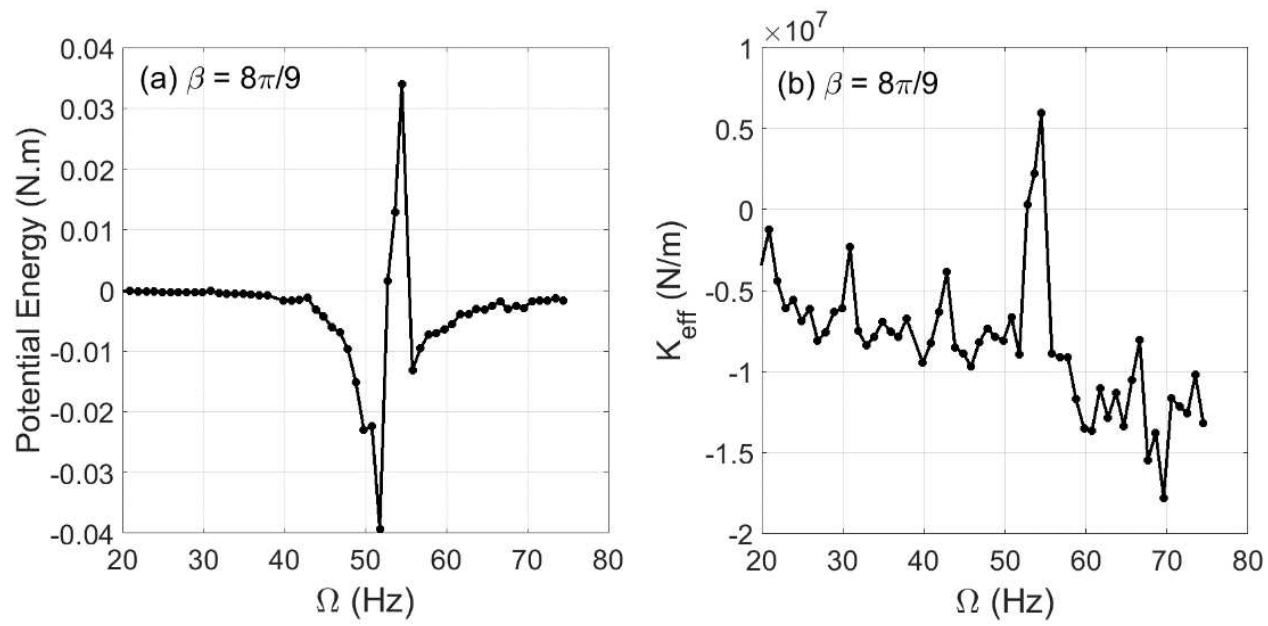

Figure 11 Experimental results in steady-state response of potential energy content in (a) and the corresponding effective stiffness content in (b) for varying shaft rotational speeds at $\mu=0.2$ and $\alpha=25 \mathrm{rad} / \mathrm{s}^{2}$ of the horizontal cracked rotor system.

\subsection{Transient Response}

The response of horizontal cracked rotor system for transient operations is obtained for Eq. (3) by numerical integration for both open and breathing crack models. Accordingly, the numerical and experimental whirl amplitudes and velocities are obtained for potential energy and effective stiffness calculations according to Eqs. (15) and (17).

\subsubsection{Open crack model}

The effect of open crack propagation and unbalance force vector orientation on the negative potential energy and stiffness content in the transient response at which a passage through resonance rotational speed takes place is shown in Figures 12 for $\alpha=25 \mathrm{rad} / \mathrm{s}^{2}$ and in Figure 13 for $\alpha=50 \mathrm{rad} / \mathrm{s}^{2}$. It is observed that the crack depth and unbalance force vector angles have a significant impact on the extent and level of negative potential and stiffness zones. Wider zones of high negative potential energy are more observed at the post resonance rotational speeds rather than the pre-resonance rotational speeds. These highest levels of negative potential are observed near to $\beta=\pi / 2$ at $\alpha=50 \mathrm{rad} / \mathrm{s}^{2}$ and significantly 
affected by crack depth propagation for both angular acceleration rates as shown from the gray-scale colored bar.
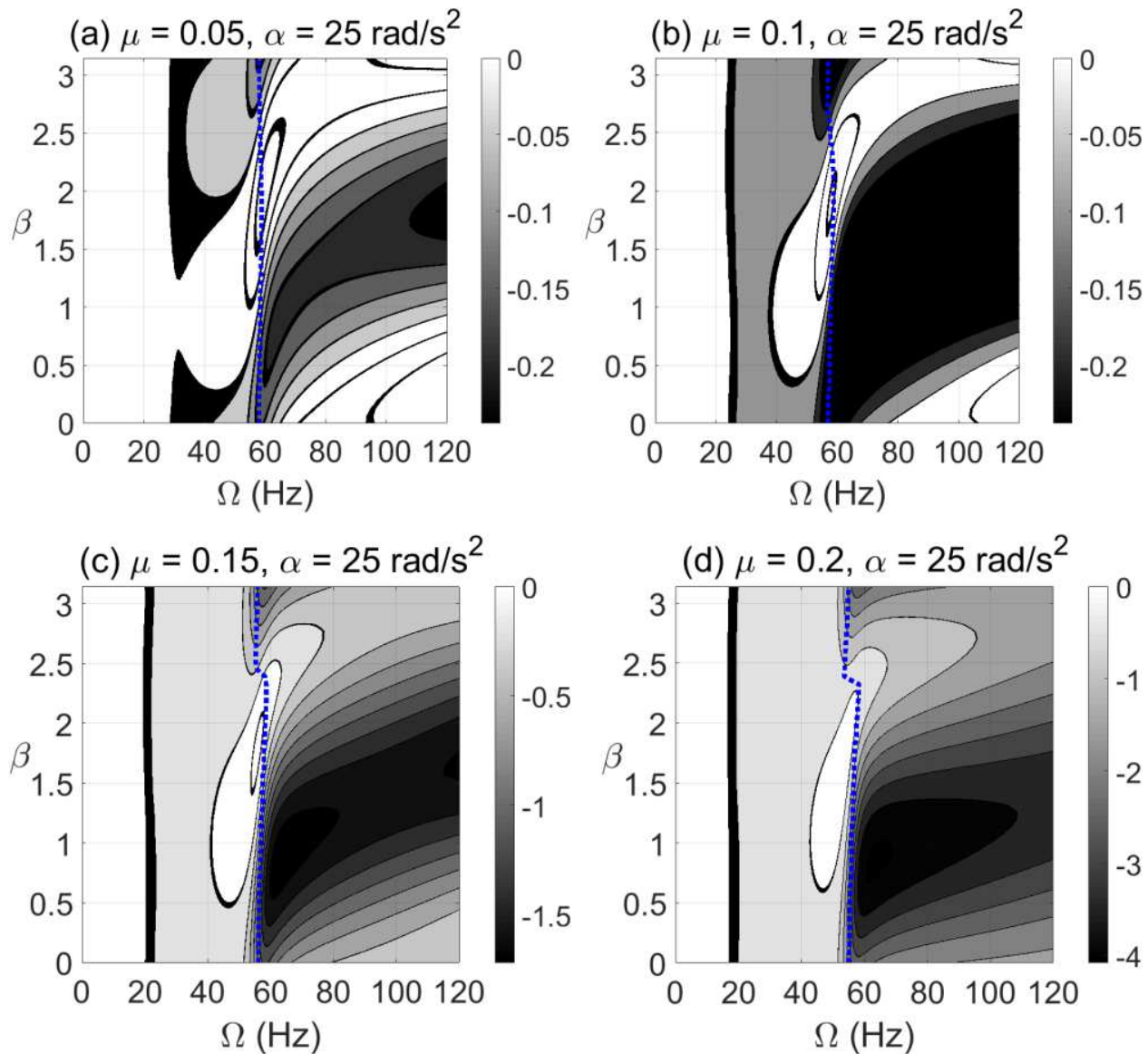

Figure 12 Effect of unbalance force vector angle $\beta$ at varying shaft rotational speeds for $\alpha=25 \mathrm{rad} / \mathrm{s}^{2}$ on the potential energy content in transient response at open crack depths $\mu=0.05$ in (a), $\mu=0.1$ in (b), $\mu=0.15$ in (c) and $\mu=0.2$ in (d). 

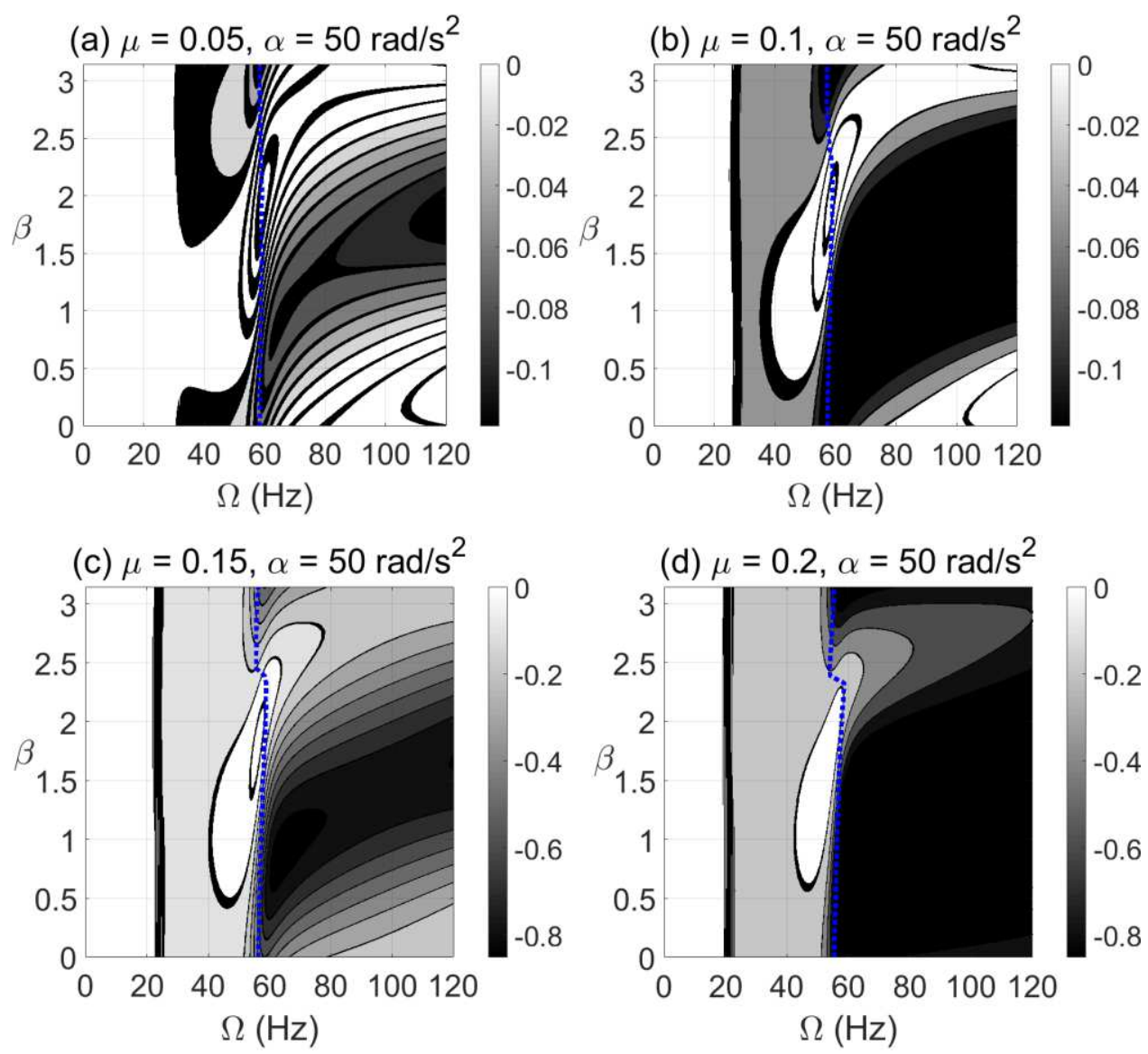

Figure 13 Effect of unbalance force angle $\beta$ at varying shaft rotational speeds for $\alpha=50 \mathrm{rad} / \mathrm{s}^{2}$ on the potential energy content in transient response at open crack depths $\mu=0.05$ in (a), $\mu=0.1$ in (b), $\mu=0.15$ in (c) and $\mu=0.2$ in (d).

\subsubsection{Breathing crack model}

The effect of breathing crack propagation on negative potential and effective stiffness zones during shaft's transient operation is shown in Figures 14 and 15 at $\alpha=25 \mathrm{rad} / \mathrm{s}^{2}$ and $\alpha=50 \mathrm{rad} / \mathrm{s}^{2}$, respectively, for different crack depths and unbalance force vector orientations. It is clearly observed that the crack depth and unbalance force vector orientation have also a significant impact on the extent and intensity of the negative potential zones. Extended zones of negative potential for a wide range of rotational speeds are observed at higher crack depths. The behavior near $1 / 2,1 / 3$ and $2 / 3$ of resonance rotational speed of the cracked system with breathing crack model in transient response in Figures 14 and 15 is somehow close to that in Figure 8 for steady-state response of similar rotor configuration with breathing crack model. 

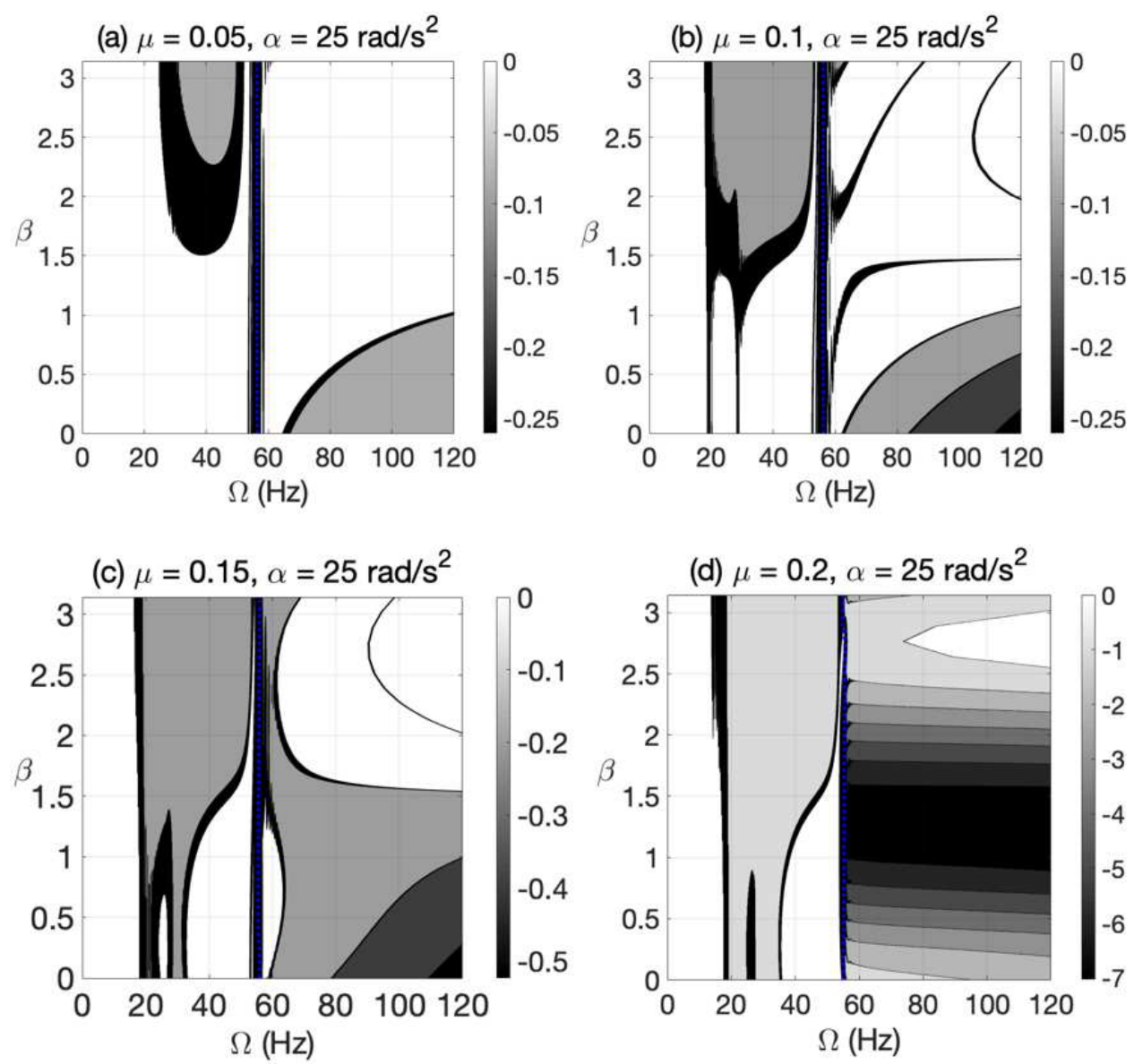

Figure 14 Effect of unbalance force vector angle $\beta$ at varying shaft rotational speeds for $\alpha=25 \mathrm{rad} / \mathrm{s}^{2}$ on the potential energy content in transient response at breathing crack depths $\mu=0.05$ in (a), $\mu=0.1$ in (b), $\mu=0.15$ in (c) and $\mu=0.2$ in (d). 

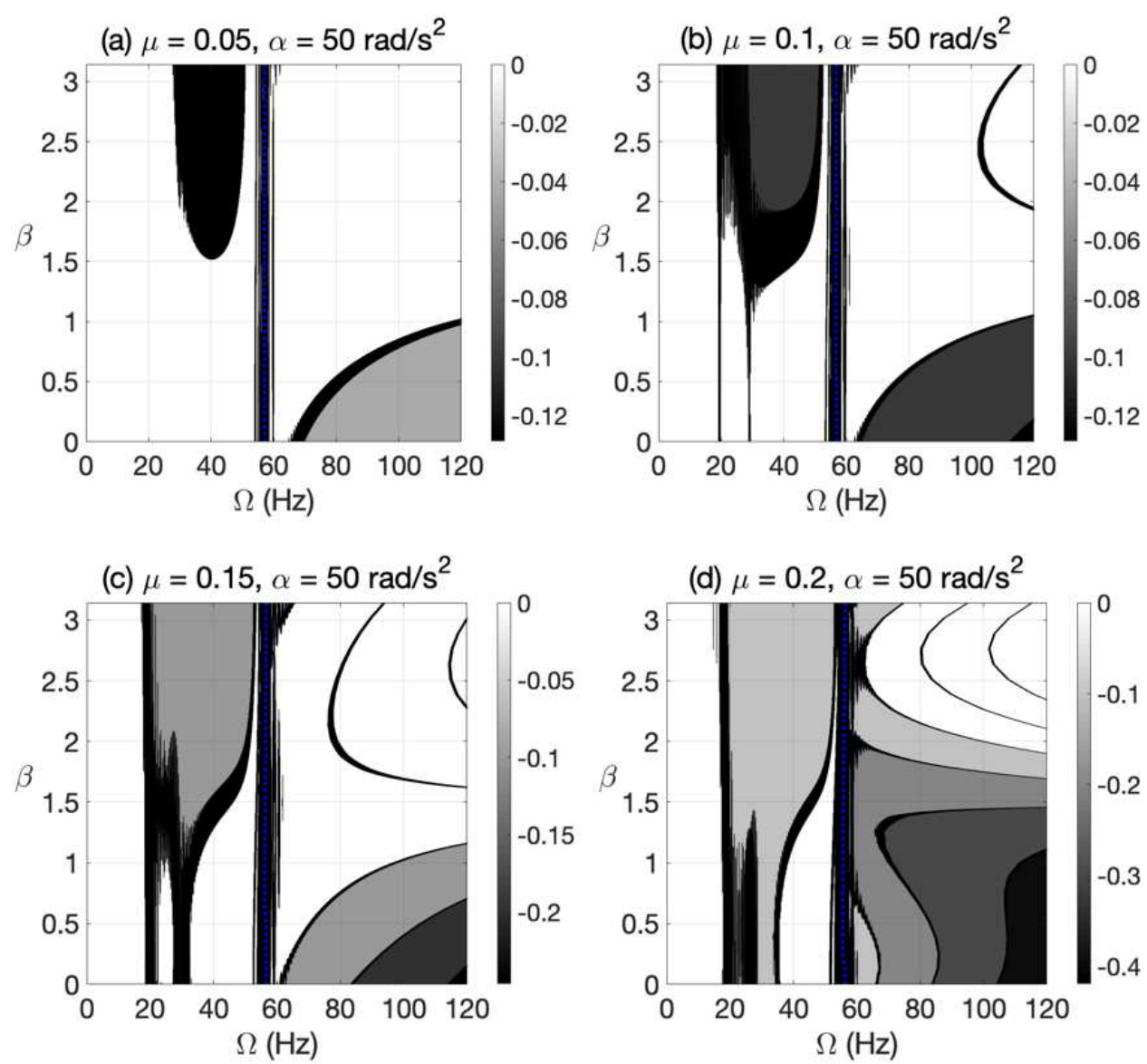

Figure 15 Effect of unbalance force vector angle $\beta$ at varying shaft rotational speeds for $\alpha=50 \mathrm{rad} / \mathrm{s}^{2}$ on the potential energy content in transient response at breathing crack depths $\mu=0.05$ in (a), $\mu=0.1$ in (b), $\mu=0.15$ in (c) and $\mu=0.2$ in (d).

\subsubsection{Experimental results}

To verify the numerical simulation findings of the accelerated shaft in transient response, both numerical and experimental whirl responses for horizontal and vertical whirl amplitudes are employed with Eqs. (15) and (17) for effective stiffness and potential energy calculations. Accordingly, the numerical simulation results of effective stiffness content in Figure (16) are compared with the experimental results in Figure (17) for various values of unbalance force vector angles. It is observed that the zones of rotational speeds at which $K_{\text {eff }}>0$ precedes the critical whirl speed zone in both numerical and experimental results for wide range of unbalance force vector angles. In addition, both numerical and experimental results show that the post-resonance zone of rotational speeds is 
dominated by $K_{\text {eff }}<0$ for all of the selected values of unbalance force vector angles.

Therefore, the experimental effective stiffness results in Figure (17) are found in good agreement with the numerical simulation prediction in Figure (16) and Figure $(12 \mathrm{~d})$.
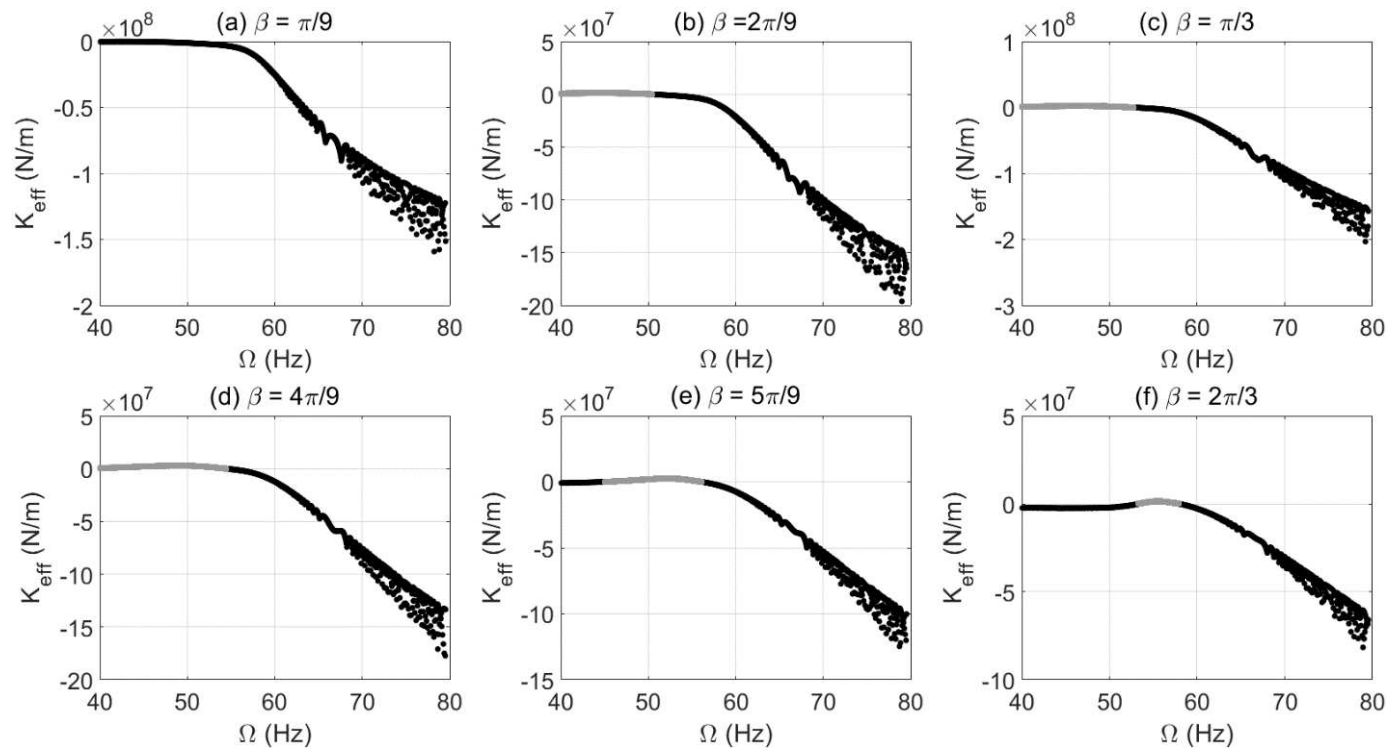

Figure 16 Numerical simulation results in transient response of effective stiffness content at different unbalance force angles and varying shaft rotational speeds for $\alpha=25 \mathrm{rad} / \mathrm{s}^{2}$ and $\mu=0.2$ (gray color: $K_{\text {eff }}>0$ )
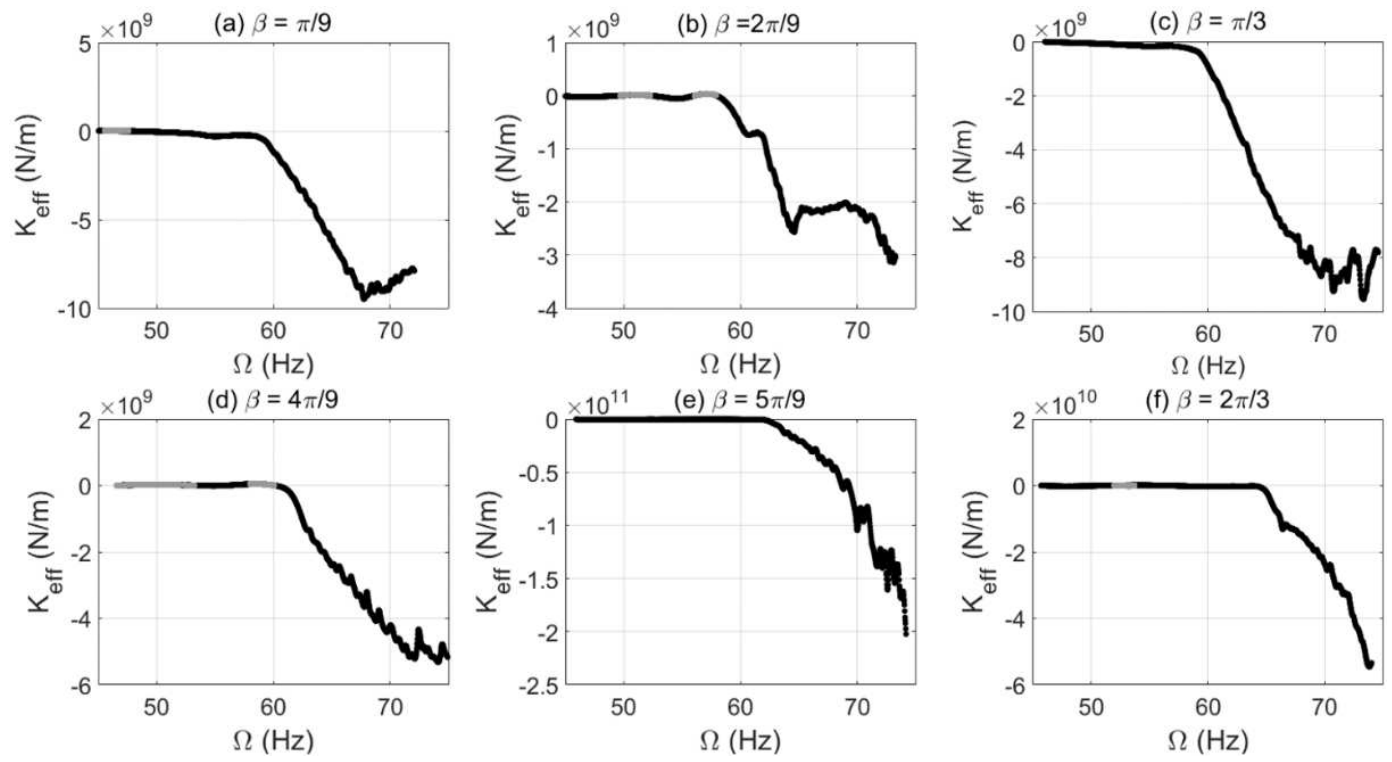

Figure 17 Experimental results of effective stiffness content in transient response at different unbalance force angles and varying shaft rotational speeds for $\alpha=25 \mathrm{rad} / \mathrm{s}^{2}$ and $\mu=0.2$ (gray color: $\left.K_{\text {eff }}>0\right)$ 


\section{Remarks on Findings}

In the crack-free system, the negative stiffness content has not been captured in both steady-state and transient operations of the rotor system. However, in all of previous numerical and experimental results for steady-state and transient operations, it has been observed that the level of negative effective stiffness content is strongly affected by the transition from the pre-resonance to post-resonance zones of rotational speeds. The cracked shaft behaves like a buckled beam in its whirl orbit of rotation where the negative stiffness is generated due to the interaction between the time-periodic or time-varying stiffness content with the unbalance force excitation at steady-state and transient operations. It can be stated that during the bending of the rotating cracked shaft in its whirl orbit, the negative effective stiffness could indicate to that the shaft is more capable to further bending from its centerline. However, for positive effective stiffness the shaft seems to be stiffer for further bending from its centerline. Accordingly, the shaft during whirling could behave like a compressed static rod at both ends where bending from its centerline (buckling) takes place under the effect of the unbalance force excitation rather than end axial loads. Similar to the compressed rod, the shaft tends to resist bending toward its centerline and tends to be less stiff to bend away from the centerline. Accordingly, at the vicinity of resonance rotational speed, the negative stiffness content might result in severe vibration whirl amplitudes, leading to failure and complete damage as the crack keeps its propagation.

\section{Conclusions}

The Jeffcott rotor model is considered here to investigate the effect of interaction between the crack depth and the change in unbalance force vector orientation on potential energy and effective stiffness content in cracked rotor 
systems during transient or steady-state operations. The breathing and open crack models at steady-state and transient operations are considered in this study. The expression of the effective stiffness in the cracked rotor system has been obtained from direct integration of equations of motion. It has been found that there is a wide zones of rotational speeds and unbalance force vector angles at which high negative stiffness content appears in the numerical and experimental whirl responses of the considered crack rotor system. Therefore, the cracked rotor system in the vicinity of the resonance rotational speeds exhibits high levels of negative stiffness content where further crack propagation at several unbalance force vector angles put the system at high risk of rapid failure. The findings in this paper suggests analyzing the potential energy content in cracked rotors whirl response as a potential damage detection tool.

\section{Funding}

The authors are grateful for the support provided by Khalifa University of Science and Technology for affording the experimental setup.

\section{Conflict of Interest}

The authors declare no competing interests.

\section{References}

1. AL-Shudeifat, M. A. On the finite element modeling of the asymmetric cracked rotor. Journal of sound and vibration 332(11), 2795-2807 (2013). https://doi.org/10.1016/j.jsv.2012.12.026

2. Jun, O. S. \& Gadala, M. S. Dynamic behavior analysis of cracked rotor. Journal of Sound and Vibration 309(1-2), 210-245 (2008). https://doi.org/10.1016/j.jsv.2007.06.065

3. Varney, P. \& Itzhak, G. Crack detection in a rotor dynamic system by vibration monitoring-Part II: extended analysis and experimental results. Journal of Engineering for Gas Turbines and Power 134(11), 112501 (2012). https://doi.org/10.1115/1.4007275

4. Kulesza, Z. \& Jerzy, T. S., Auxiliary state variables for rotor crack detection. Journal of Vibration and Control 17(6), 857-872 (2011). https://doi.org/10.1177/1077546309360050

5. Bachschmid, N., Paolo, P., Ezio, T. \& Vania, A. Identification of transverse crack position and depth in rotor systems. Meccanica 35(6), 563-582 (2000). https://doi.org/10.1023/A:1010562205385 
6. Kulesza, Z., Jerzy \& T. S Rigid finite element model of a cracked rotor. Journal of Sound and Vibration 331(18), 4145-4169 (2012). https://doi.org/10.1016/j.jsv.2012.04.014

7. Sekhar, A. S. Vibration characteristics of a cracked rotor with two open cracks. Journal of Sound and Vibration 223(4), 497-512 (1999). https://doi.org/10.1006/jsvi.1998.2120

8. Mohiuddin, M. A. \& Khulief, Y. A. Dynamic response analysis of rotor-bearing systems with cracked shaft. Journal of Mechanical Design 124(4), 690-696 (2002). https://doi.org/10.1115/1.1423950

9. Sekhar, A. S. \& Prabhu, B. S. Transient analysis of a cracked rotor passing through critical speed. Journal of Sound Vibration 173(3), 415-421 (1994).

https://doi.org/10.1006/jsvi.1994.1238

10. Sekhar, A. S., Mohanty, A. R. \& Prabhakar, S. Vibrations of cracked rotor system: transverse crack versus slant crack. Journal of Sound and Vibration 279(3-5), 1203-1217 (2005). https://doi.org/10.1016/j.jsv.2004.01.011

11. Prabhakar, S., Sekhar, A. S. \& Mohanty, A. R. Transient lateral analysis of a slant-cracked rotor passing through its flexural critical speed. Mechanism and machine theory 37(9), 10071020 (2002). https://doi.org/10.1016/S0094-114X(02)00020-4

12. Prabhakar, S., Sekhar, A. S. \& Mohanty, A. R. Crack versus coupling misalignment in a transient rotor system. Journal of sound and vibration 256(4), 773-786 (2002). https://doi.org/10.1006/jsvi.2001.4225

13. AL-Shudeifat, M. A. New backward whirl phenomena in intact and cracked rotor systems. Journal of Sound and Vibration 443, 124-138 (2019). https://doi.org/10.1016/j.jsv.2018.11.038

14. AL-Shudeifat, M. A., Shiryayev, O., Al Hammadi, F., Alzarooni, T. \& Nataraj, C. Postresonance backward whirl in accelerating cracked rotor systems. European Journal of Mechanics-A/Solids 83,104039 (2020). https://doi.org/10.1016/j.euromechsol.2020.104039

15. Alzarooni, T., AL-Shudeifat, M. A., Shiryayev, O. \& Nataraj, C. Breathing Crack Model Effect on Rotor's Post-resonance Backward Whirl. Journal of Computational and Nonlinear Dynamics 15(12), 121007 (2020). https://doi.org/10.1115/1.4048358

16. Ramesh, B. T., Srikanth, S. \& Sekhar, A. S. Hilbert-Huang transform for detection and monitoring of crack in a transient rotor. Mechanical Systems and Signal Processing 22(4), 905-914 (2008). https://doi.org/10.1016/j.ymssp.2007.10.010

17. Guo, D. \& Peng, Z. K. Vibration analysis of a cracked rotor using Hilbert-Huang transform. Mechanical Systems and Signal Processing 21(8), 3030-3041 (2007). https://doi.org/10.1016/j.ymssp.2007.05.004

18. Dong, G. M., Chen, J. \& Zou, J. Parameter identification of a rotor with an open crack. European Journal of Mechanics-A/Solids. 23(2), 325-333 (2004). https://doi.org/10.1016/j.euromechsol.2003.11.003

19. Collins, K. R., Plaut, R.H. \& Wauer, J. Detection of cracks in rotating Timoshenko shafts using axial impulses. Journal of vibration and acoustics 113(1), 74-78 (1991). https://doi.org/10.1115/1.2930158

20. Gounaris, G. D. \& Papadopoulos, C. A. Crack identification in rotating shafts by coupled response measurements. Engineering Fracture Mechanics 69(3), 339-352 (2002). https://doi.org/10.1016/S0013-7944(01)00076-5

21. Dong, G. M. \& Chen, J. (2009) Crack identification in a rotor with an open crack. Journal of mechanical science and technology 23(11), 2964-2972. https://doi.org/10.1007/s12206-009$\underline{0814-5}$ 
22. Kulesza, Z. Dynamic behavior of cracked rotor subjected to multisine excitation. Journal of Sound and Vibration 333(5), 1369-1378 (2014). https://doi.org/10.1016/j.jsv.2013.10.031

23. Kamel, M. \& Bauomy, H. S. Nonlinear behavior of a rotor-AMB system under multiparametric excitations. Meccanica 45(1), 7-22 (2010). https://doi.org/10.1007/s11012-0099213-3

24. Eissa, M., Kamel, M. \& Bauomy, H. S. (2012) Dynamics of an AMB-rotor with time varying stiffness and mixed excitations. Meccanica 47(3), 585-601. https://doi.org/10.1007/s11012$\underline{011-9469-2}$

25. Seibold, S. \& Weinert, K. A time domain method for the localization of cracks in rotors. Journal of sound and vibration 195(1), 57-73 (1996). https://doi.org/10.1006/jsvi.1996.0403

26. Mohammed, A. A., Neilson, R. D., Deans, W. F. \& MacConnell, P. Crack detection in a rotating shaft using artificial neural networks and PSD characterization. Meccanica 49(2), 255-266 (2014). https://doi.org/10.1007/s11012-013-9790-Z

27. Darpe, A. K. A novel way to detect transverse surface crack in a rotating shaft. Journal of sound and vibration 305(1-2), 151-171 (2007). https://doi.org/10.1016/j.jsv.2007.03.070

28. Chasalevris, A. C. \& Papadopoulos, C. A. Coupled horizontal and vertical bending vibrations of a stationary shaft with two cracks. Journal of Sound and Vibration 309(3-5), 507-528 (2008). https://doi.org/10.1016/j.jsv.2007.07.039

29. Papadopoulos, C. A. \& Dimarogonas, A. D. Coupled longitudinal and bending vibrations of a rotating shaft with an open crack. Journal of sound and vibration 117(1), 81-93 (1987). https://doi.org/10.1016/0022-460X(87)90437-8

30. Guo, C., AL-Shudeifat, M. A., Yan, J., Bergman, L. A., McFarland, D. M. \& Butcher, E. A. Stability analysis for transverse breathing cracks in rotor systems. European Journal of Mechanics-A/Solids 42, 27-34 (2013). https://doi.org/10.1016/j.euromechsol.2013.04.001

31. AL-Shudeifat, M. A. Stability analysis and backward whirl investigation of cracked rotors with time-varying stiffness. Journal of Sound and Vibration 348, 365-380 (2015). https://doi.org/10.1016/j.jsv.2015.03.007

32. Galarza-Urigoitia, N., Rubio-García, B., Gascón-Álvarez. J., Aznar-Lapuente, G., OliteBiurrun, J., López-Germán, A. \& Rubio-Botía, J. Predictive maintenance of wind turbine low-speed shafts based on an autonomous ultrasonic system. Engineering Failure Analysis 103, 481-504 (2019). https://doi.org/10.1016/j.engfailanal.2019.04.048

33. Gradzki, R., Kulesza, Z. \& Bartoszewicz, B. Method of shaft crack detection based on squared gain of vibration amplitude. Nonlinear Dynamics 98(1), 671-690 (2019). https://doi.org/10.1007/s11071-019-05221-0

34. Jiang, X., Shi, J., Huang, W. \& Zhu, Z. Non-dominated solution set based on time-frequency infograms for local damage detection of rotating machines. ISA transactions 92, 213-227 (2019). https://doi.org/10.1016/j.isatra.2019.02.023

35. Liu, Y., Zhao, Y., Lang, Z. Q., Li, J., Yan, X. \& Zhao, S. Weighted contribution rate of nonlinear output frequency response functions and its application to rotor system fault diagnosis. Journal of Sound and Vibration 460,114882 (2019). https://doi.org/10.1016/j.jsv.2019.114882

36. Liu, Y., Zhao, Y., Han, J., Meng, Q. \& Yao, H. Combination algorithm for cracked rotor fault diagnosis based on NOFRFs and HHR. Journal of Mechanical Science and Technology 33(4),1585-1593 (2019). https://doi.org/10.1007/s12206-019-0310-5

37. Bovsunovsky, A. P. Estimation of efficiency of vibration damage detection in stepped shaft of steam turbine. Electric Power Systems Research 154,381-390 (2018).

https://doi.org/10.1016/j.epsr.2017.09.012 
38. Kumar, V. R. \& Peng, Q. Nonlinear dynamic modeling of the cracked rotor ball bearing system with emphasis on damage detection capabilities. Journal of Vibration and Acoustics 140(4), 041018 (2018). https://doi.org/10.1115/1.4039404

39. Rabelo, D. S., Tsuruta, K. M., De Oliveira, D. D., Cavalini, A. A., Neto, R. F. \& Steffen, V. Fault detection of a rotating shaft by using the electromechanical impedance method and a temperature compensation approach. Journal of Nondestructive Evaluation 36(2), 25 (2017). https://doi.org/10.1007/s10921-017-0405-9

40. Mao, Y., Qin, Y. \& Zhang, A. Compound damages detection for rotors by the coupled piezoelectric impedance. IEEE Access 6,75975-75987 (2018). https://doi.org/10.1109/ACCESS.2018.2873659

41. Cruz-Vega, I., Rangel-Magdaleno, J., Ramirez-Cortes, J. \& Peregrina-Barreto, H. Automatic progressive damage detection of rotor bar in induction motor using vibration analysis and multiple classifiers. Journal of Mechanical Science and Technology 31(6), 2651-2662 (2017). https://doi.org/10.1007/s12206-017-0508-3

42. Bovsunovsky, A. \& Surace, C. Non-linearities in the vibrations of elastic structures with a closing crack: A state of the art review. Mechanical Systems and Signal Processing 62, 129148 (2015). https://doi.org/10.1016/j.ymssp.2015.01.021

43. Kumar, C. \& Rastogi, V. A brief review on dynamics of a cracked rotor. International Journal of Rotating Machinery. (2009). https://doi.org/10.1155/2009/758108

44. Nath A. G., Udmale, S. S. \& Singh, S. K. Role of artificial intelligence in rotor fault diagnosis: A comprehensive review. Artificial Intelligence Review. 1-60 (2020). https://doi.org/10.1007/s10462-020-09910-w

45. AL-Shudeifat, M. A. \& Alhammadi, F. K. Negative effective stiffness content in cracked rotors. ASME International Mechanical Engineering Congress and Exposition 52033: V04AT06A002 (2018). https://doi.org/10.1115/IMECE2018-87470

46. Friswell, M. I., Penny, J. E. T., Seamus, D. G. \& Arthur, W. L. Dynamics of rotating machines. (Cambridge University Press 2010).

47. Zapoměl, J. \& Ferfecki, P. A computational investigation on the reducing lateral vibration of rotors with rolling-element bearings passing through critical speeds by means of tuning the stiffness of the system supports. Mechanism and Machine Theory 46(5), 707-724 (2011). https://doi.org/10.1016/j.mechmachtheory.2010.12.006

48. Zapoměl, J. \& Ferfecki, P. A computational investigation of the disk-housing impacts of accelerating rotors supported by hydrodynamic bearings. Journal of applied mechanics $\mathbf{7 8}(2)$, 021001 (2011). https://doi.org/10.1115/1.4002527 


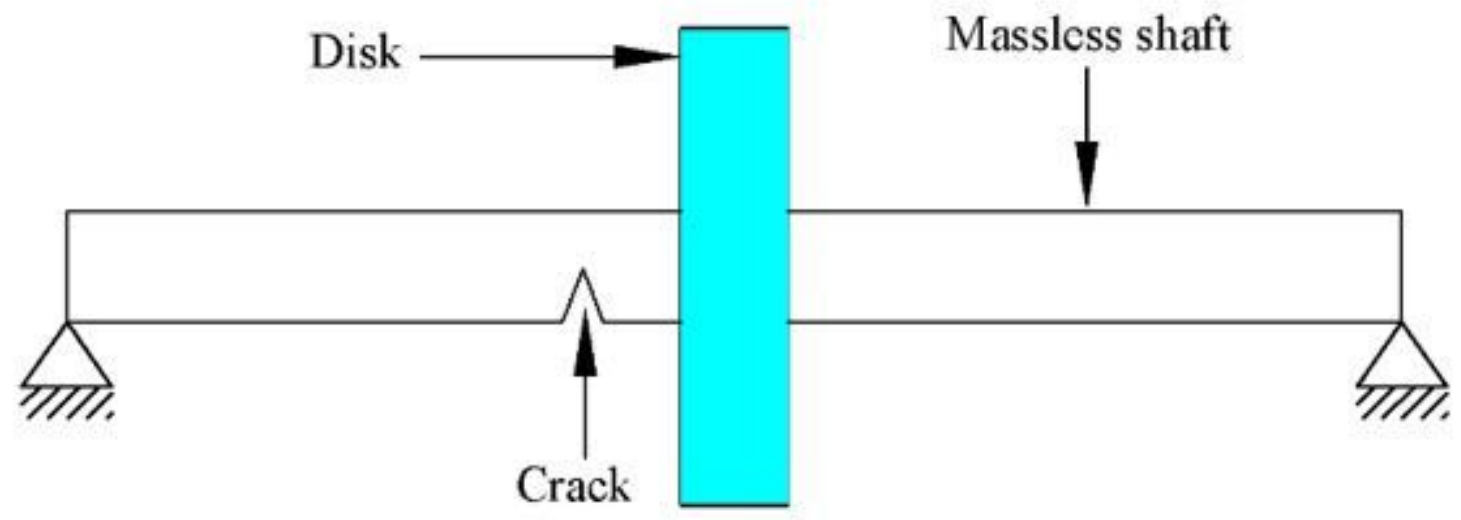

Figure 1

Jeffcott rotor with an open crack model
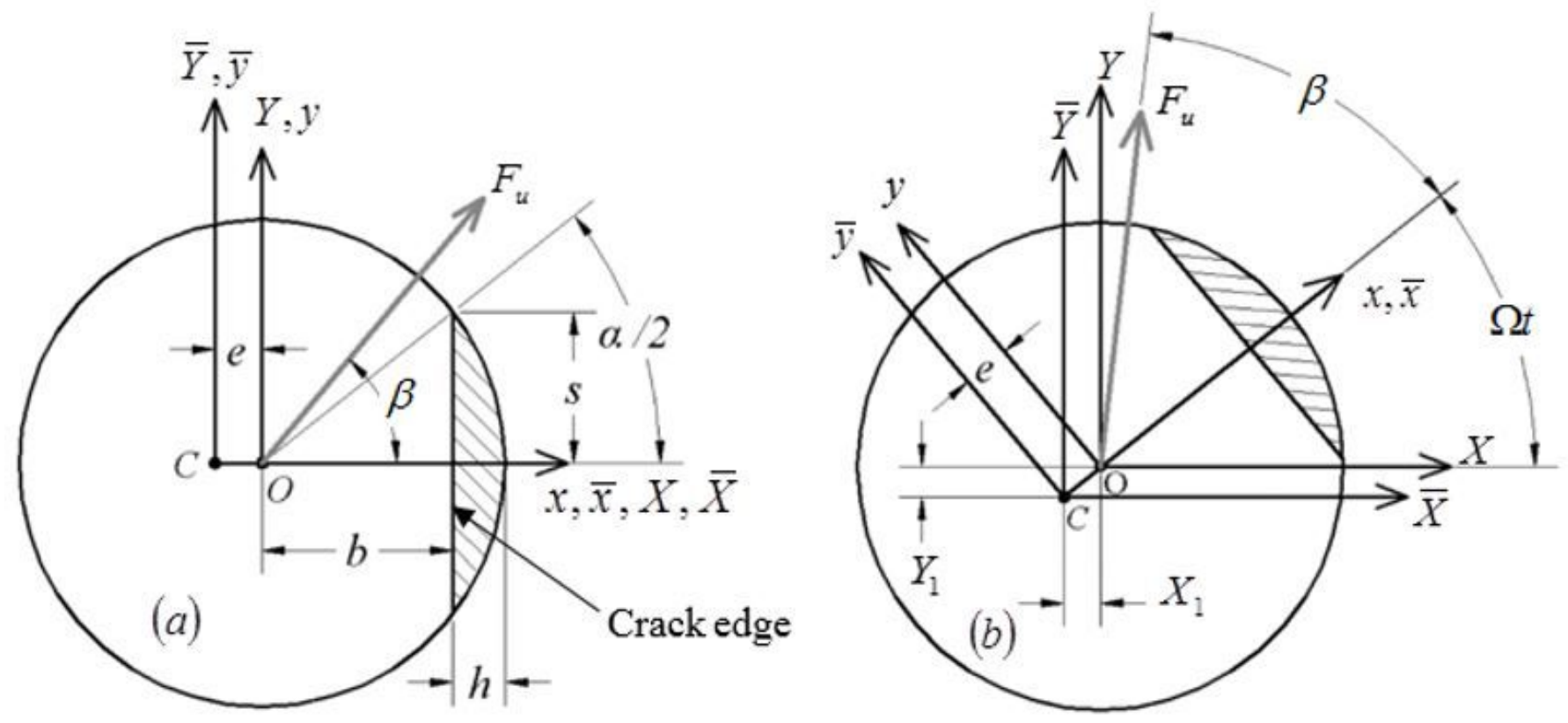

Figure 2

Schematic diagrams of the open crack in the shaft cross-section (a) before the shaft's rotation, and (b) after the shaft's rotation [13-15]. 


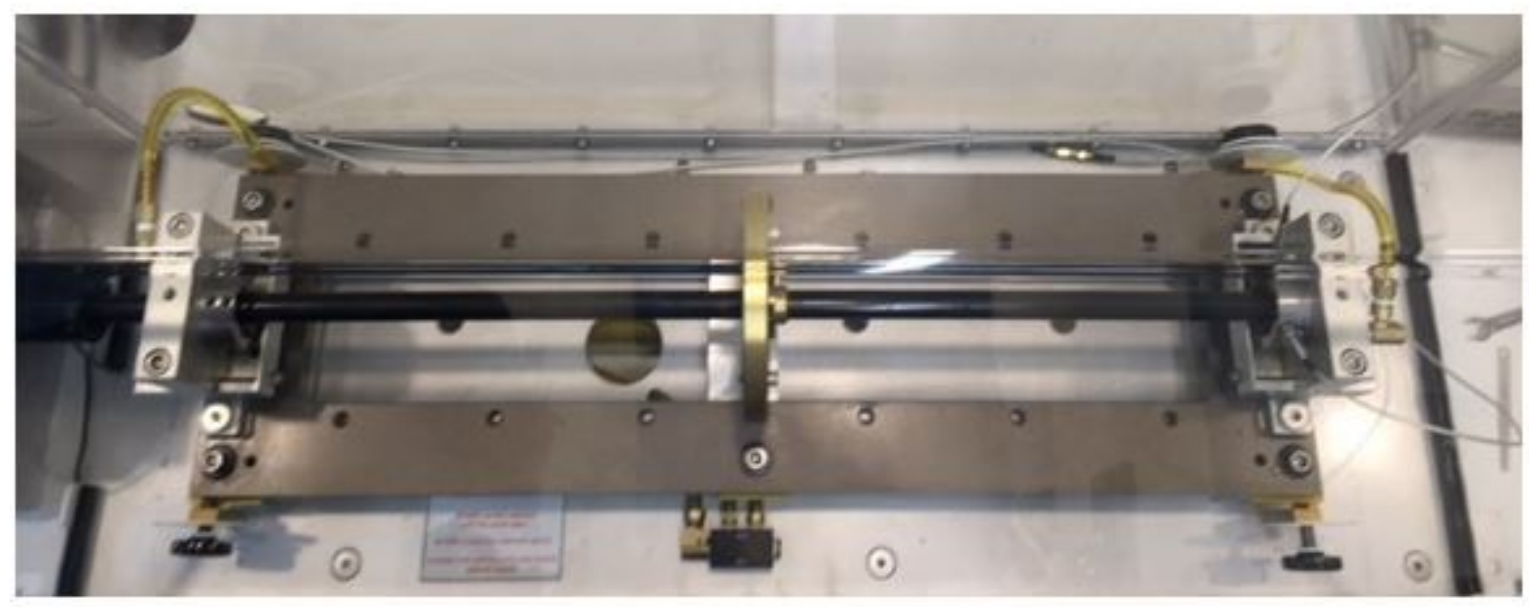

Figure 3

Spectra Quest MFS-RDS rotordynamic simulator 

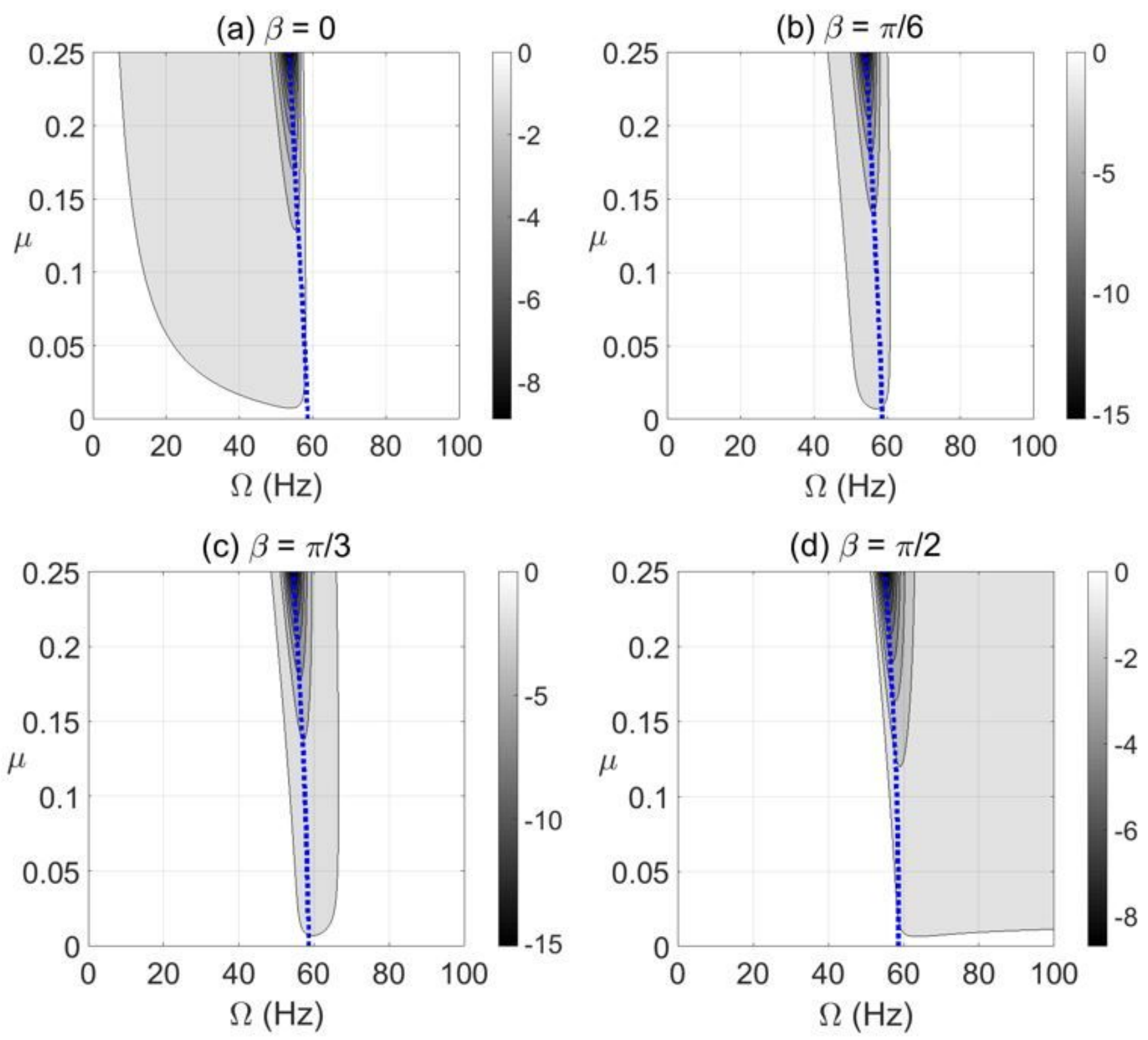

Figure 4

Effect of the open crack model depth at varying shaft rotational speeds on the potential energy content in steady-state response at unbalance force angles in (a), in (b), in (c) and in (d). 

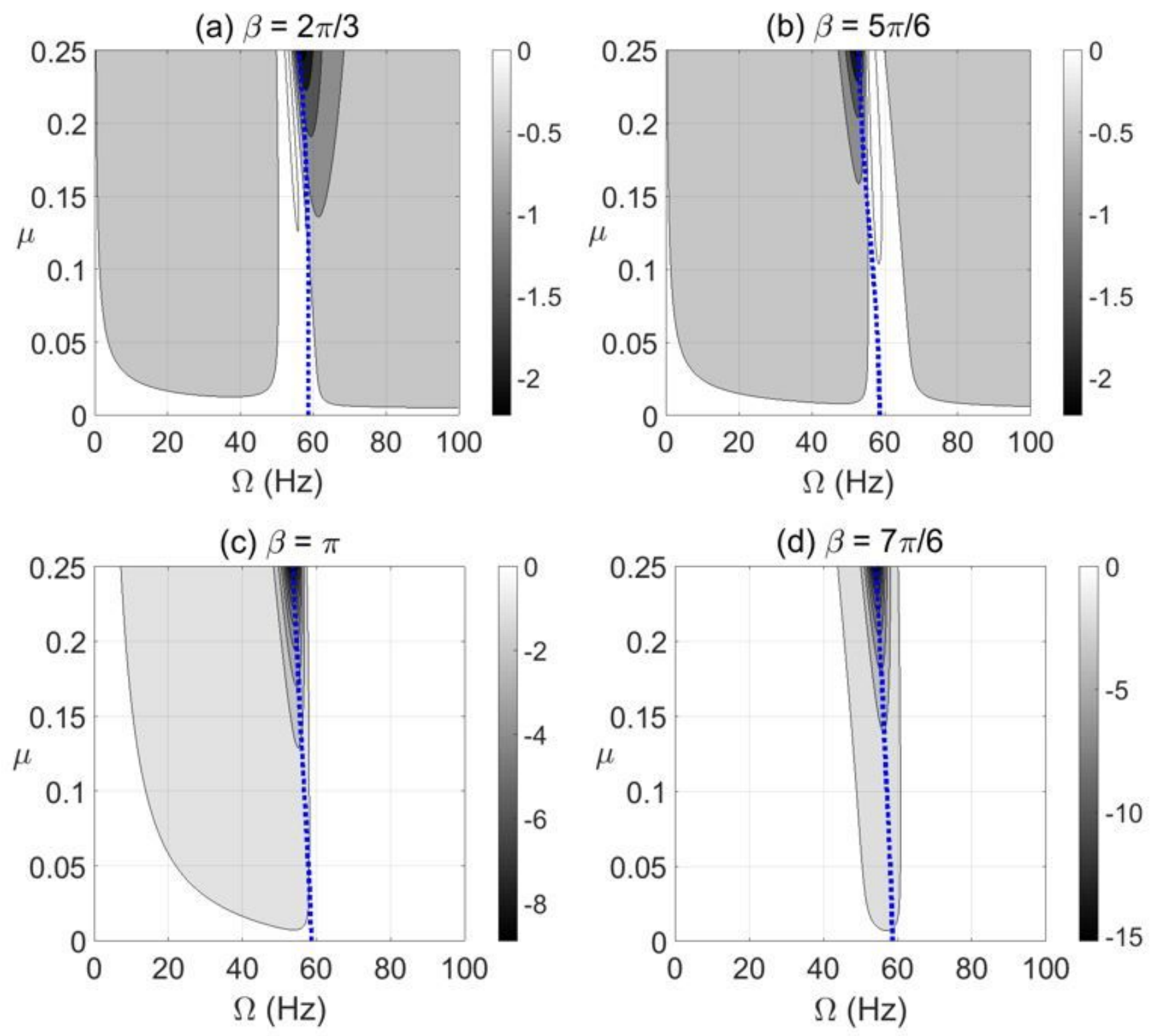

Figure 5

Effect of the open crack model depth at varying shaft rotational speeds on the potential energy content in steady-state response at unbalance force angles in (a), in (b), in (c) and in (d). 
(a) $\mu=0.05$

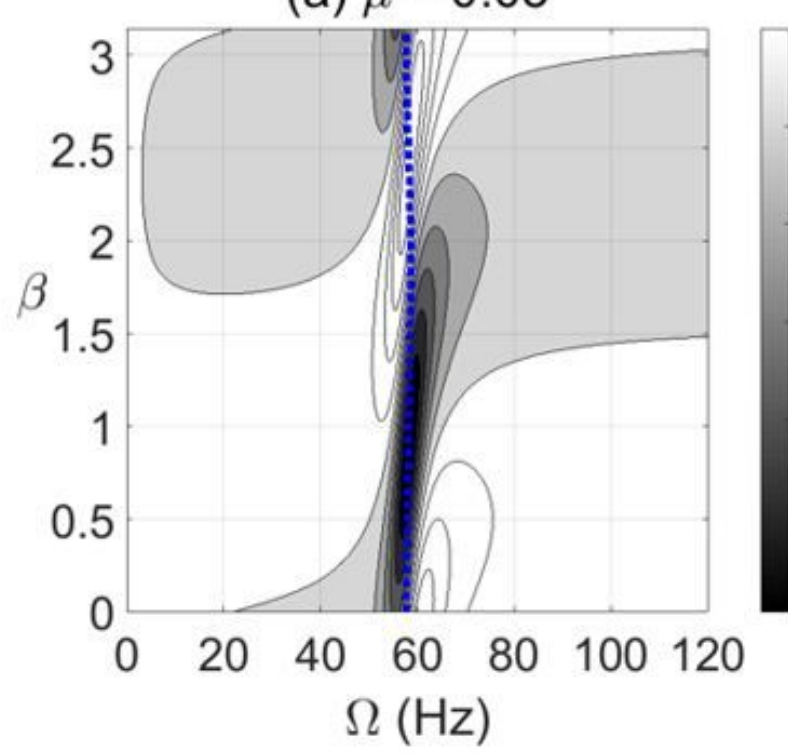

(c) $\mu=0.15$

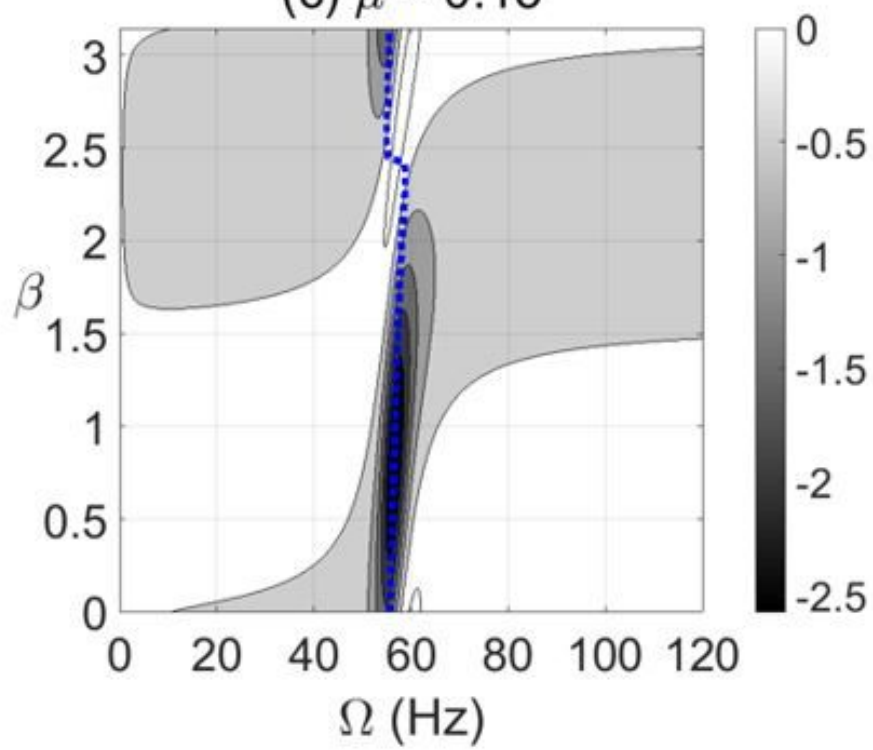

(b) $\mu=0.1$

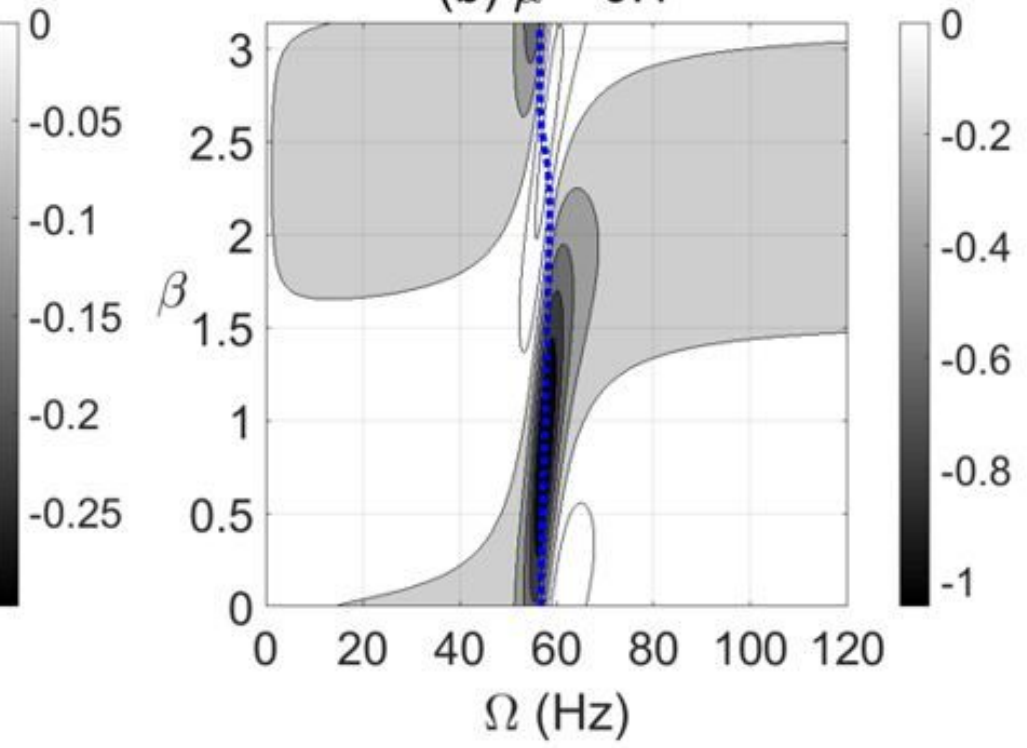

(d) $\mu=0.2$

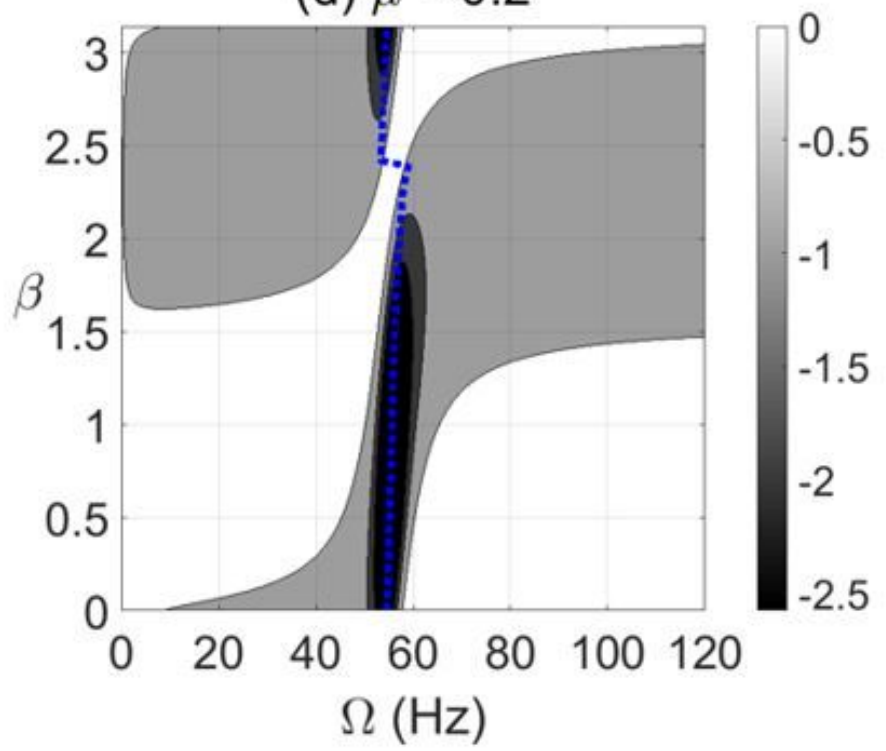

Figure 6

Effect of unbalance force vector angle at varying shaft rotational speeds on potential energy content in steady-state response of vertical cracked rotor system with open crack model depths in (a), in (b), in (c) and in (d). 
(a) $\mu=0.05$

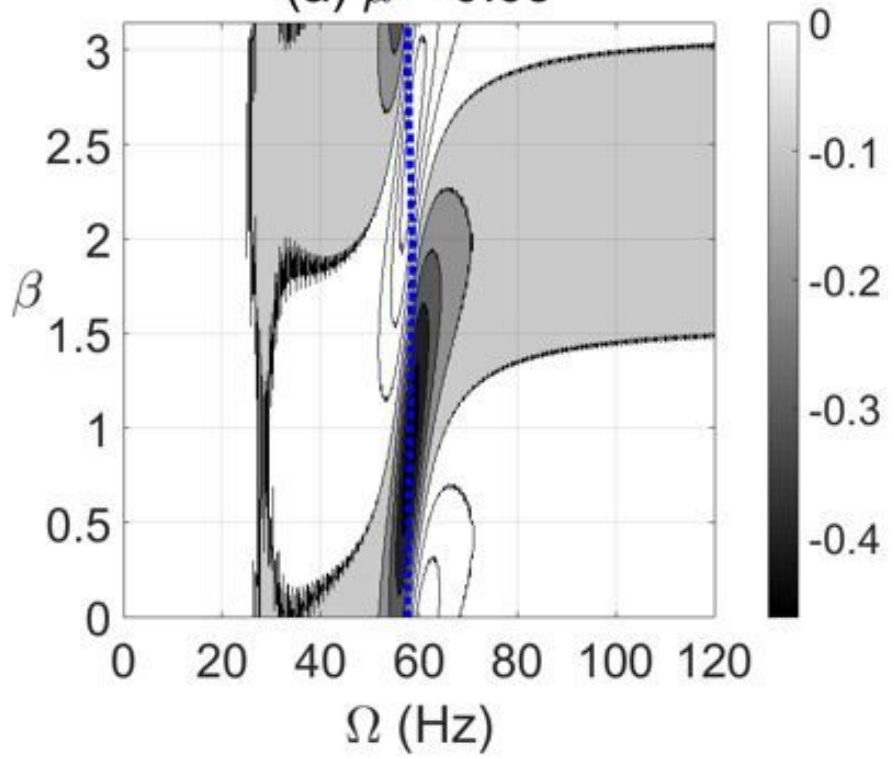

(c) $\mu=0.15$

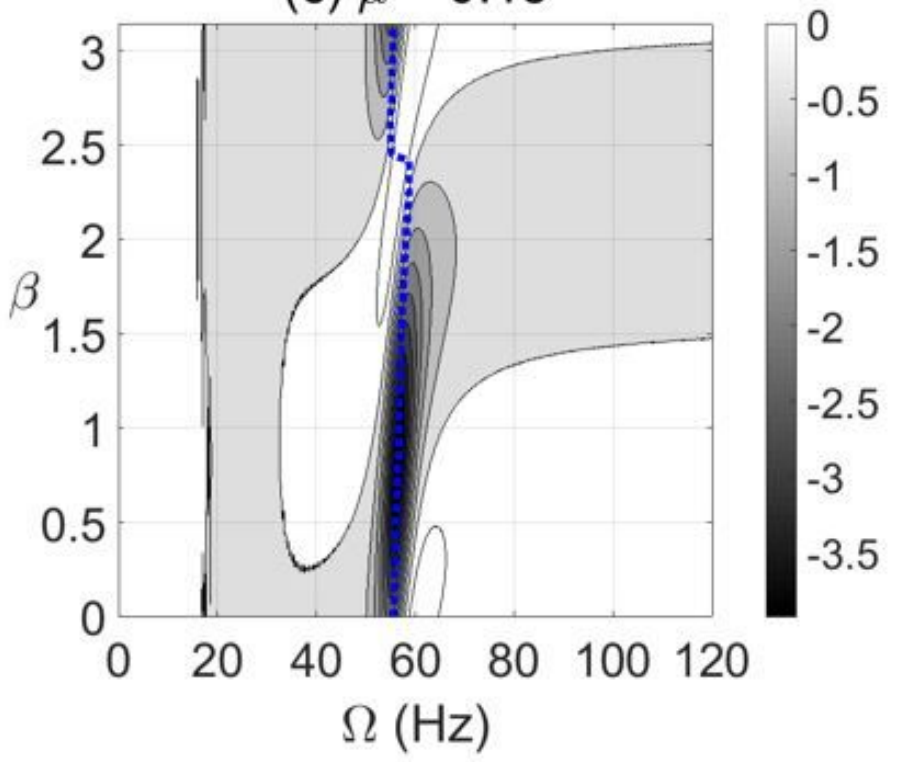

(b) $\mu=0.1$

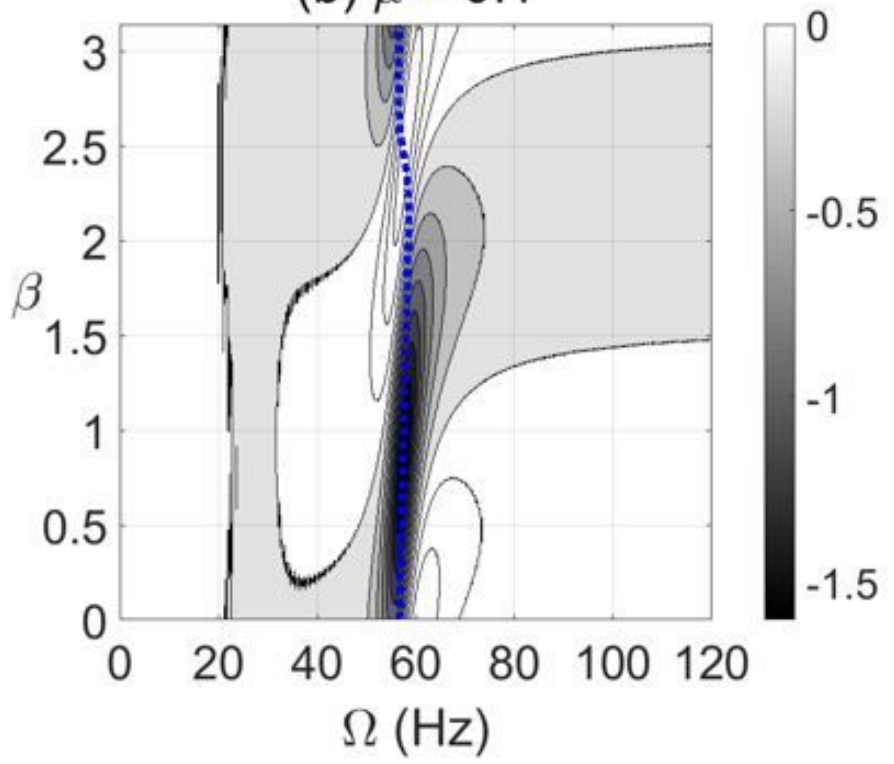

(d) $\mu=0.2$

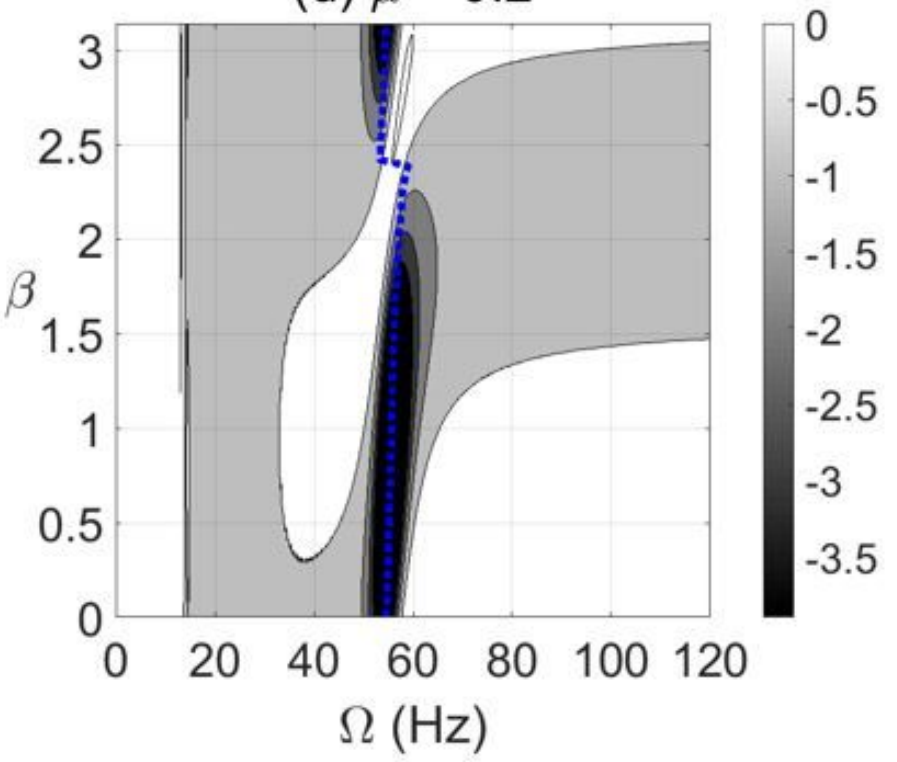

Figure 7

Effect of unbalance force vector angle at varying shaft rotational speeds on potential energy content in steady-state response of horizontal cracked rotor system with open crack model depths in (a), in (b), in (c) and in (d). 
(a) $\mu=0.05$

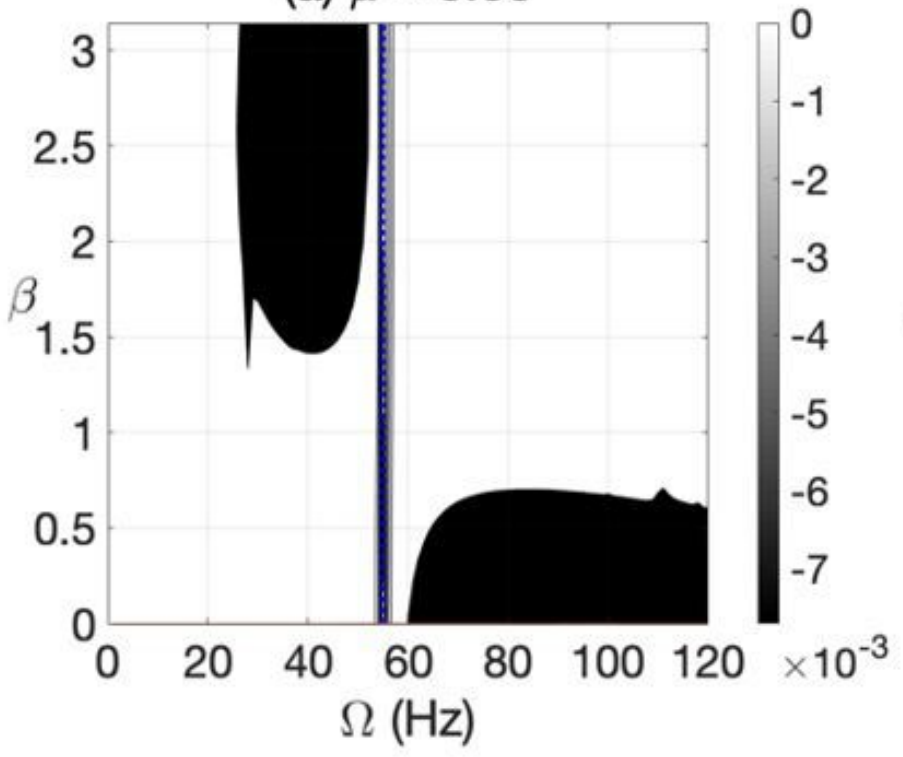

(c) $\mu=0.15$

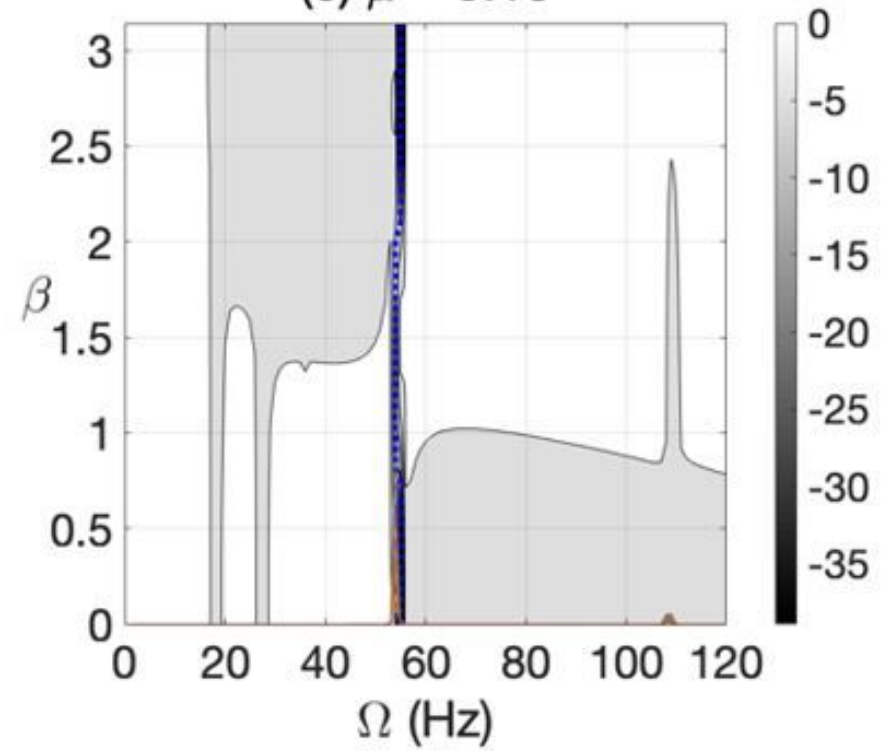

(b) $\mu=0.1$

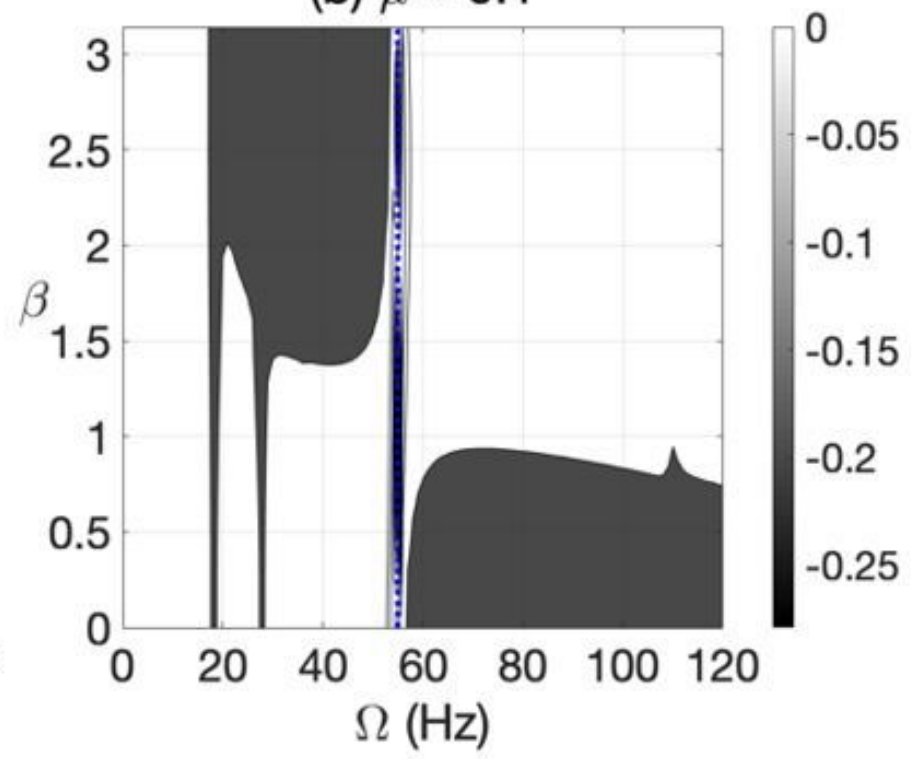

(d) $\mu=0.2$

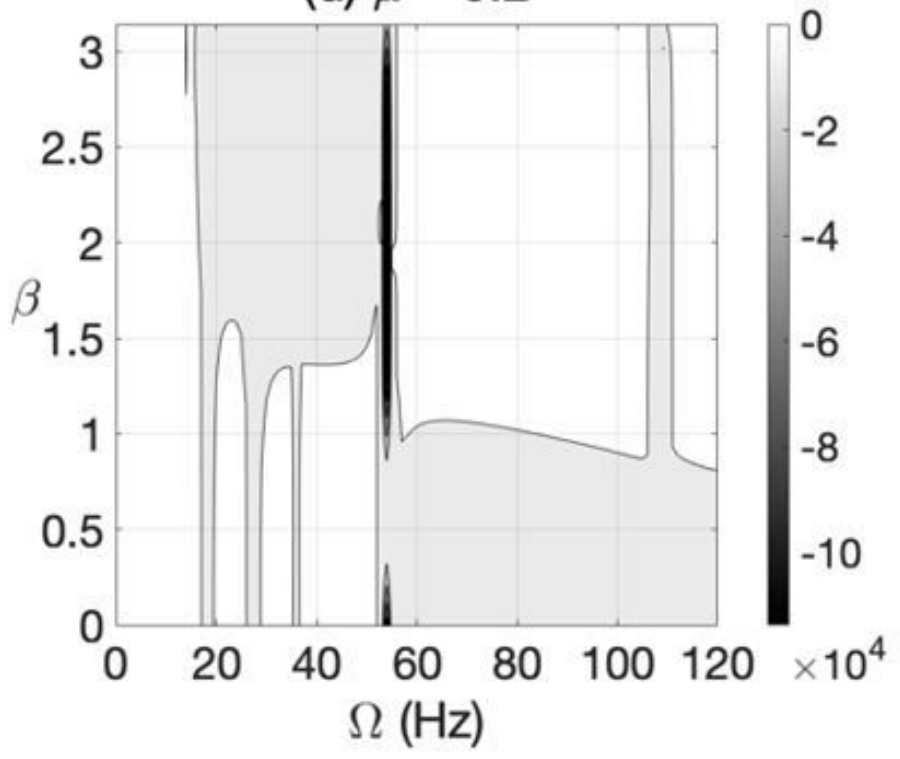

Figure 8

Effect of unbalance force vector angle at varying shaft rotational speeds on potential energy content in steady-state response of horizontal cracked rotor system with breathing crack model depths in (a), in (b), in (c) and in (d). 

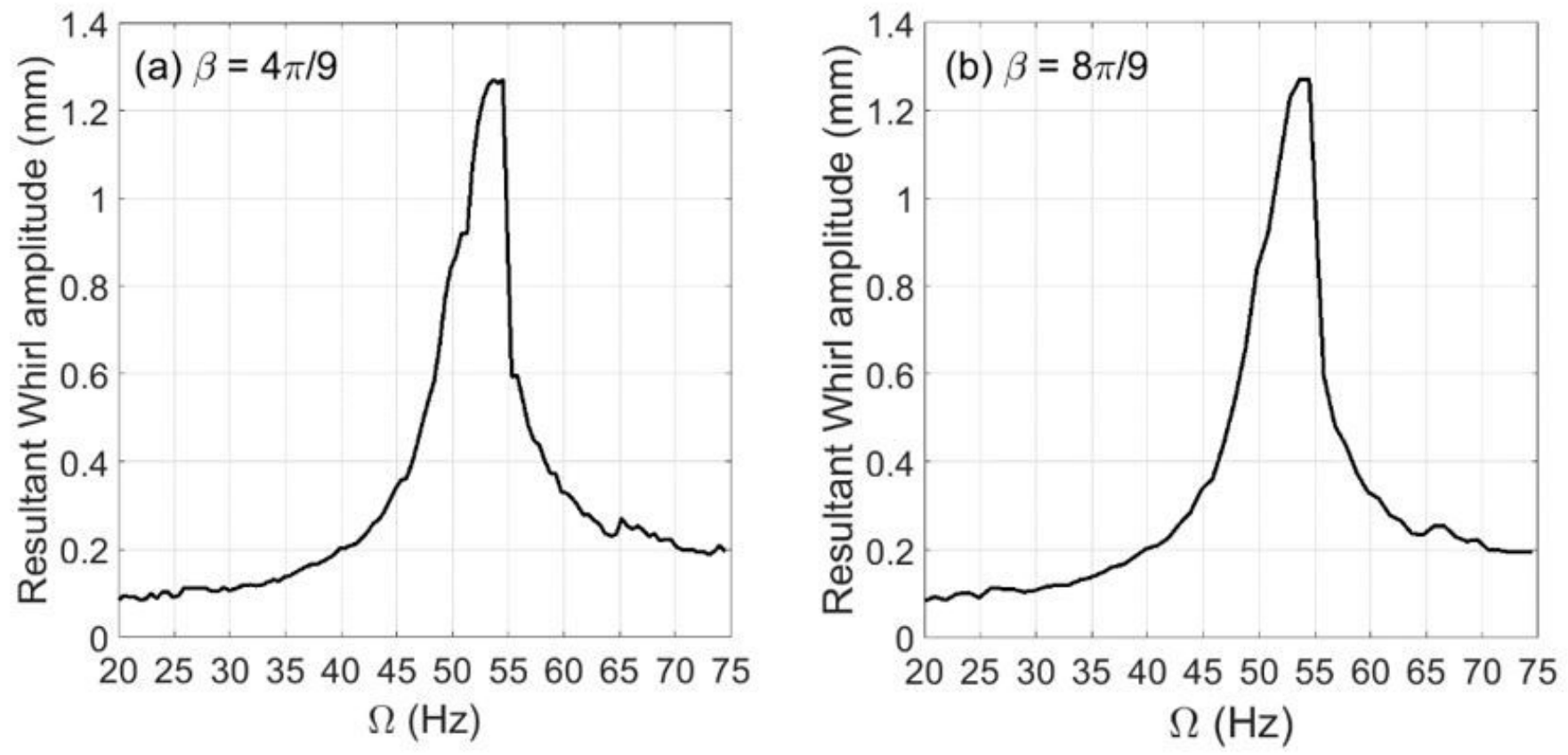

Figure 9

Experimental whirl amplitudes in steady-state response versus the shaft rotational speeds at and in (a) and in (b) of the horizontal cracked rotor system.
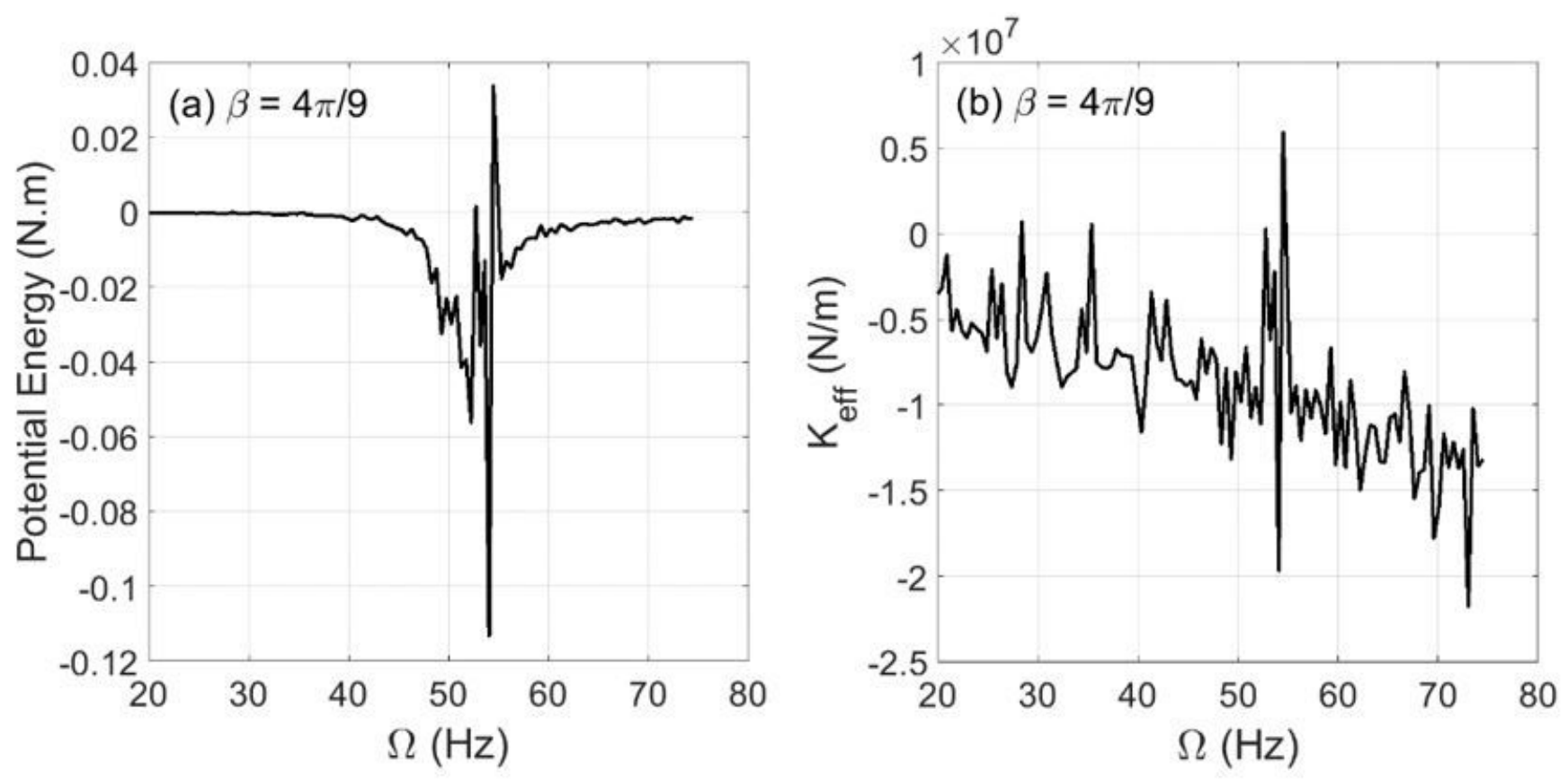

Figure 10

Experimental results in steady-state response of potential energy content in (a) and the corresponding effective stiffness content in (b) for varying shaft rotational speeds at and of the horizontal cracked rotor system. 

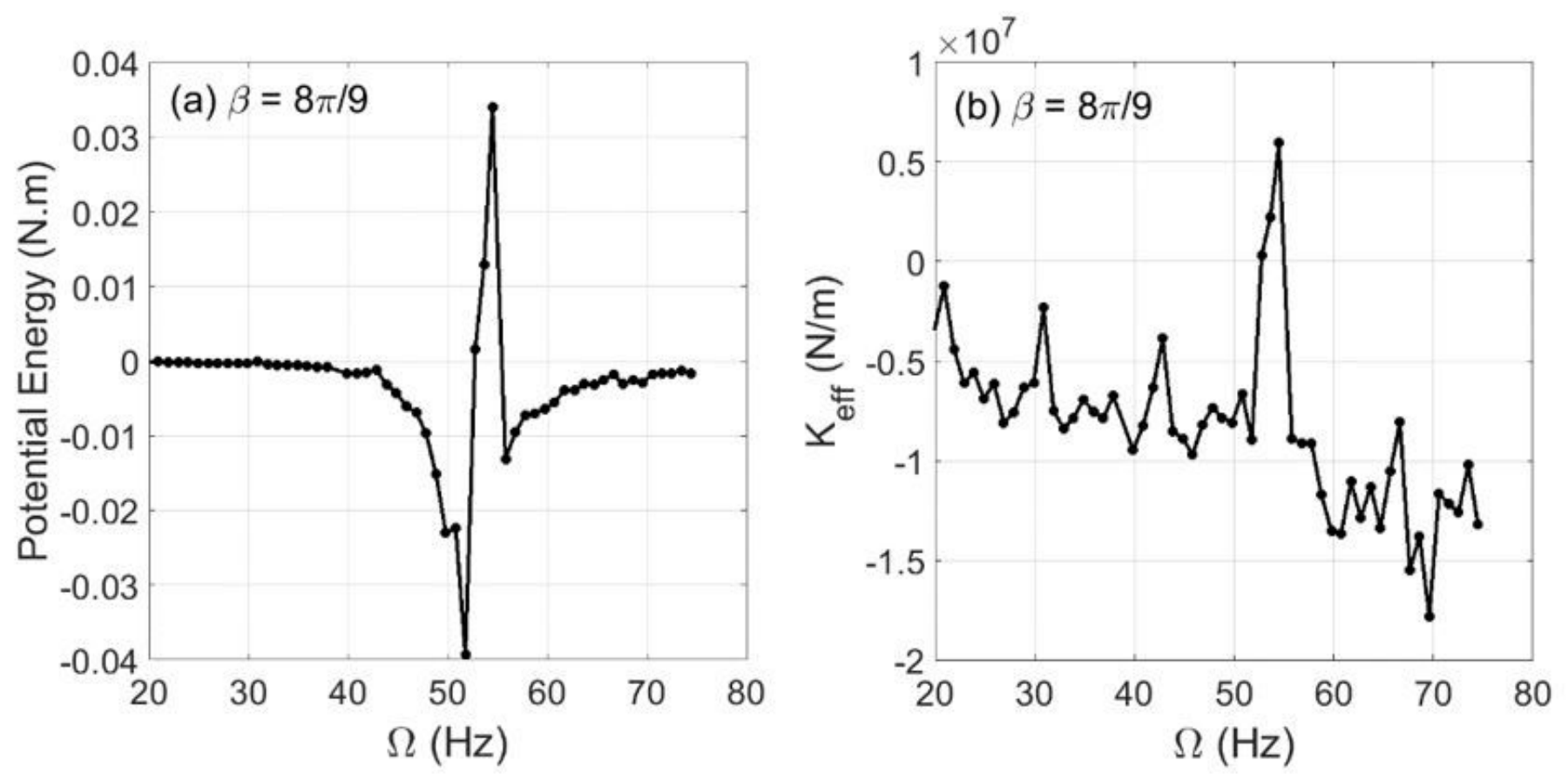

Figure 11

Experimental results in steady-state response of potential energy content in (a) and the corresponding effective stiffness content in (b) for varying shaft rotational speeds at and of the horizontal cracked rotor system. 

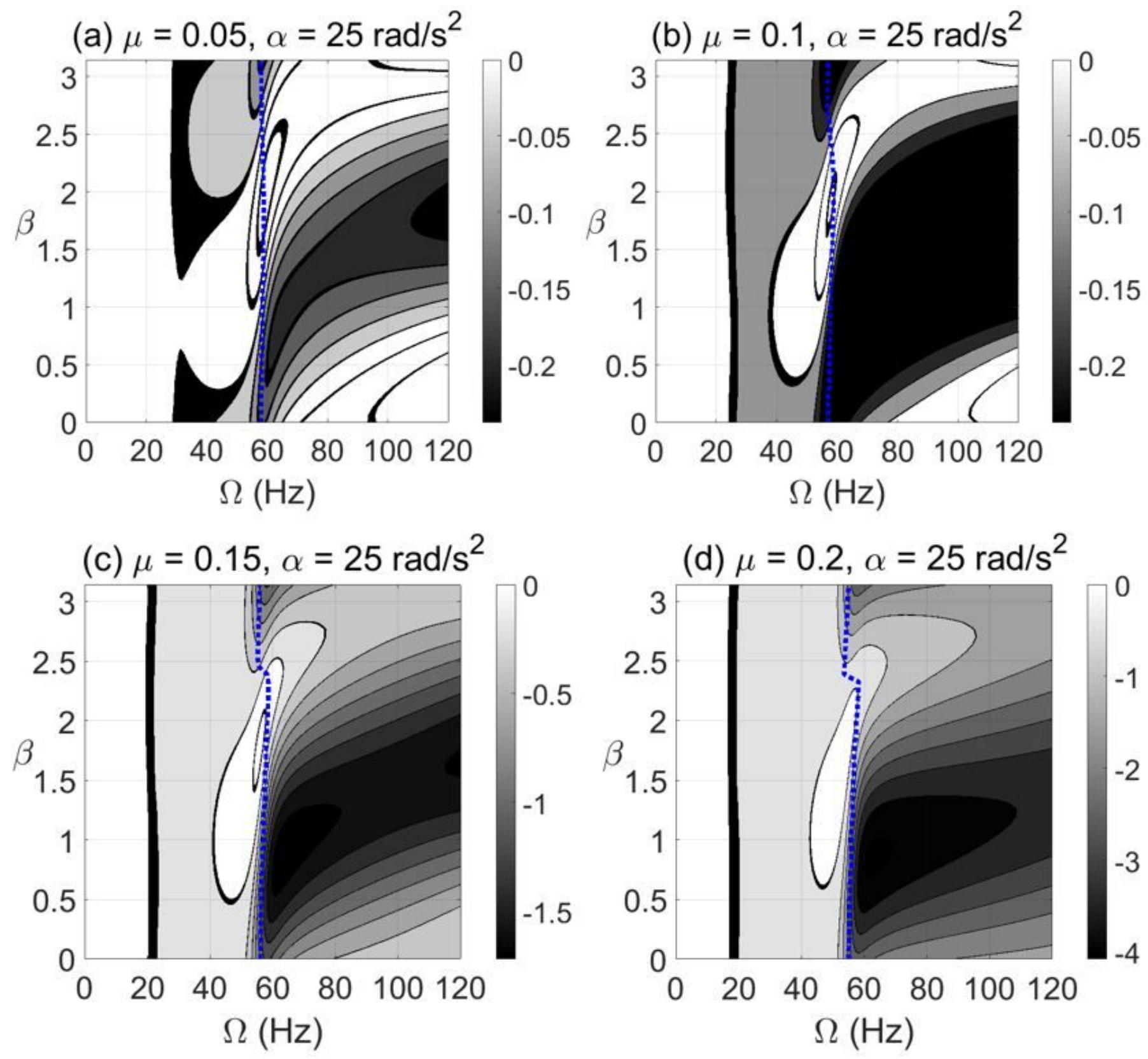

Figure 12

Effect of unbalance force vector angle at varying shaft rotational speeds for on the potential energy content in transient response at open crack depths in (a), in (b), in (c) and in (d). 

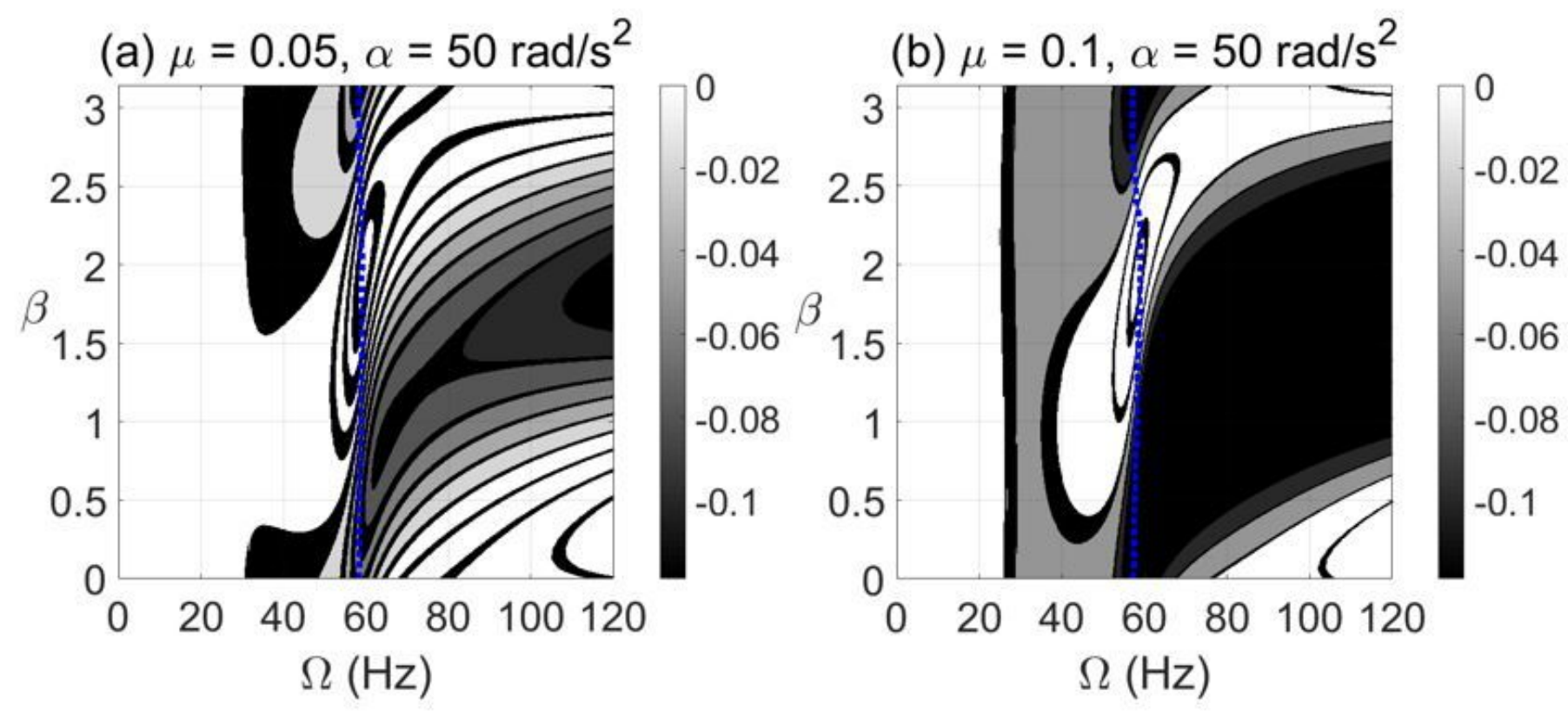

(c) $\mu=0.15, \alpha=50 \mathrm{rad} / \mathrm{s}^{2}$

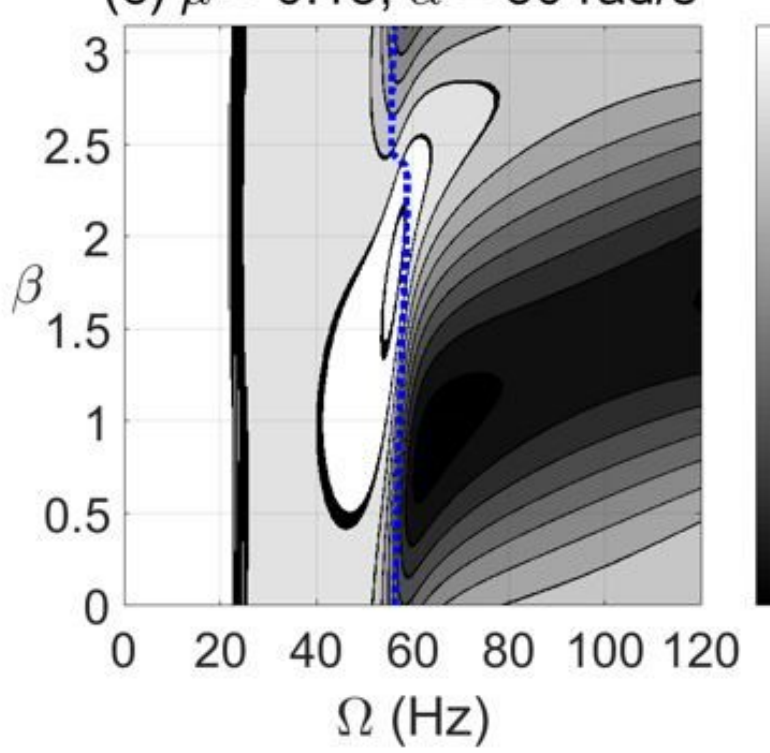

(d) $\mu=0.2, \alpha=50 \mathrm{rad} / \mathrm{s}^{2}$

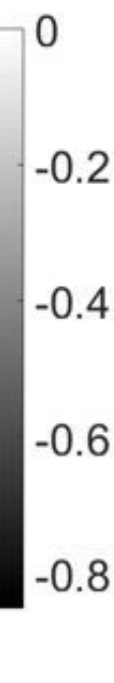

0.6

$-0.8$

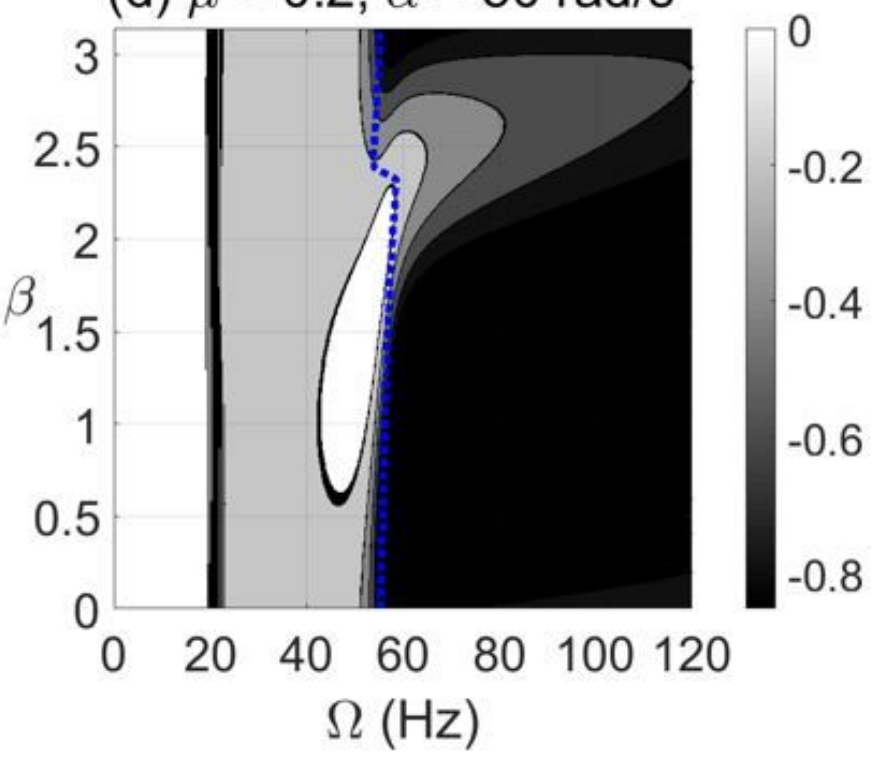

Figure 13

Effect of unbalance force angle at varying shaft rotational speeds for on the potential energy content in transient response at open crack depths in (a), in (b), in (c) and in (d). 

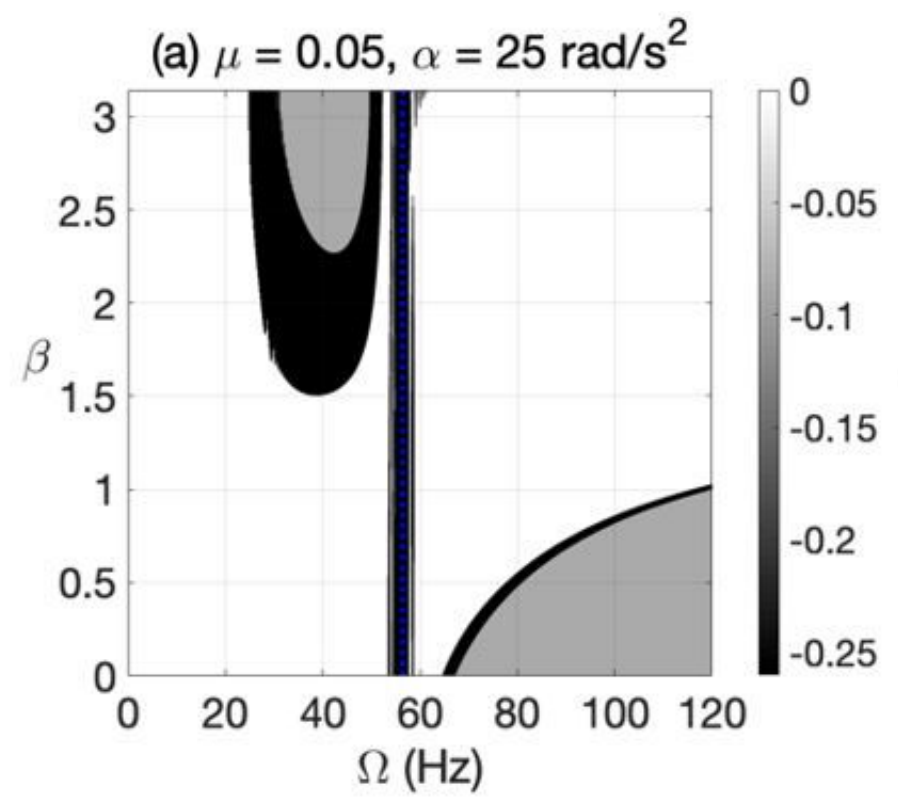

(b) $\mu=0.1, \alpha=25 \mathrm{rad} / \mathrm{s}^{2}$
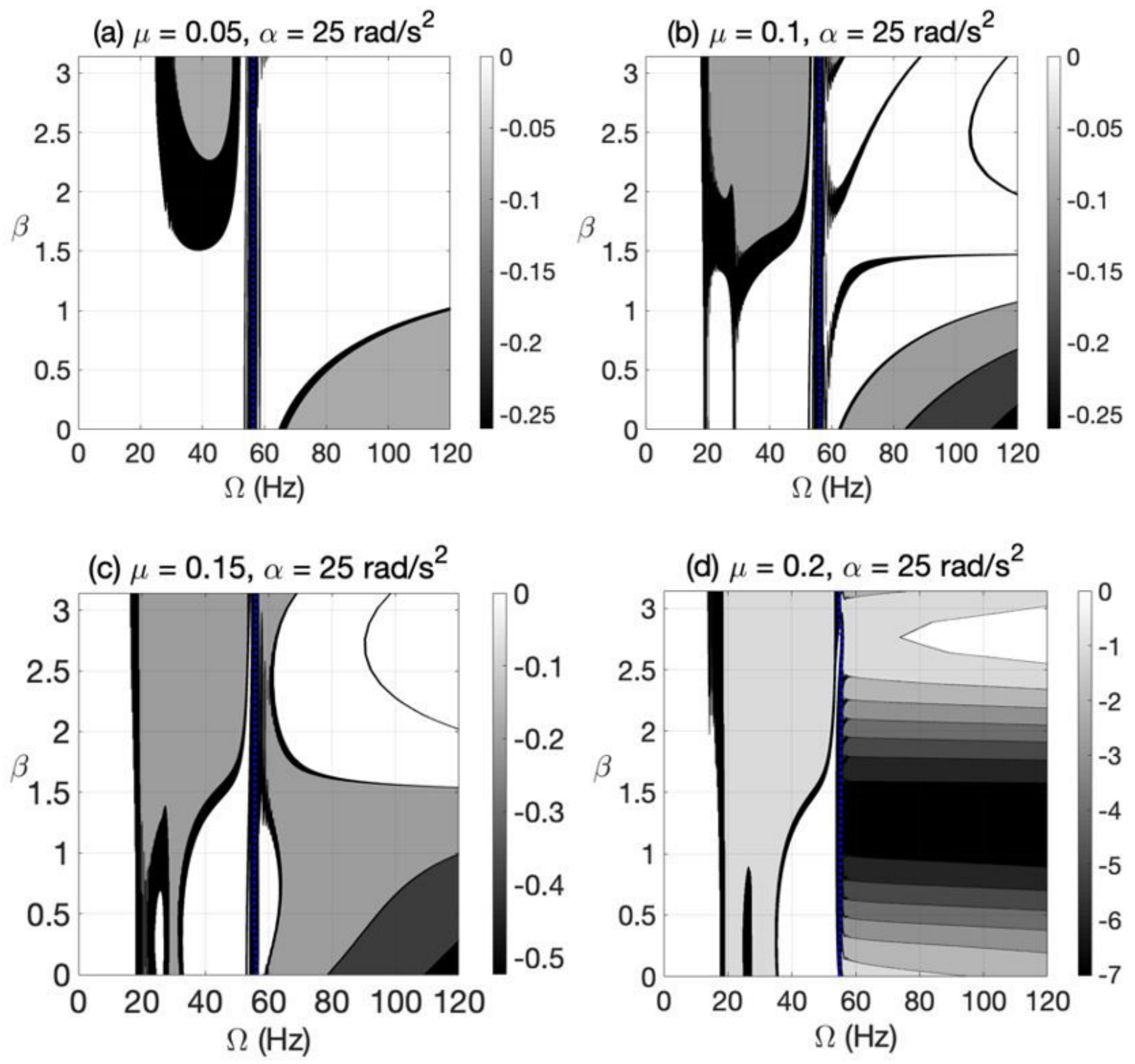

Figure 14

Effect of unbalance force vector angle at varying shaft rotational speeds for on the potential energy content in transient response at breathing crack depths in (a), in (b), in (c) and in (d). 

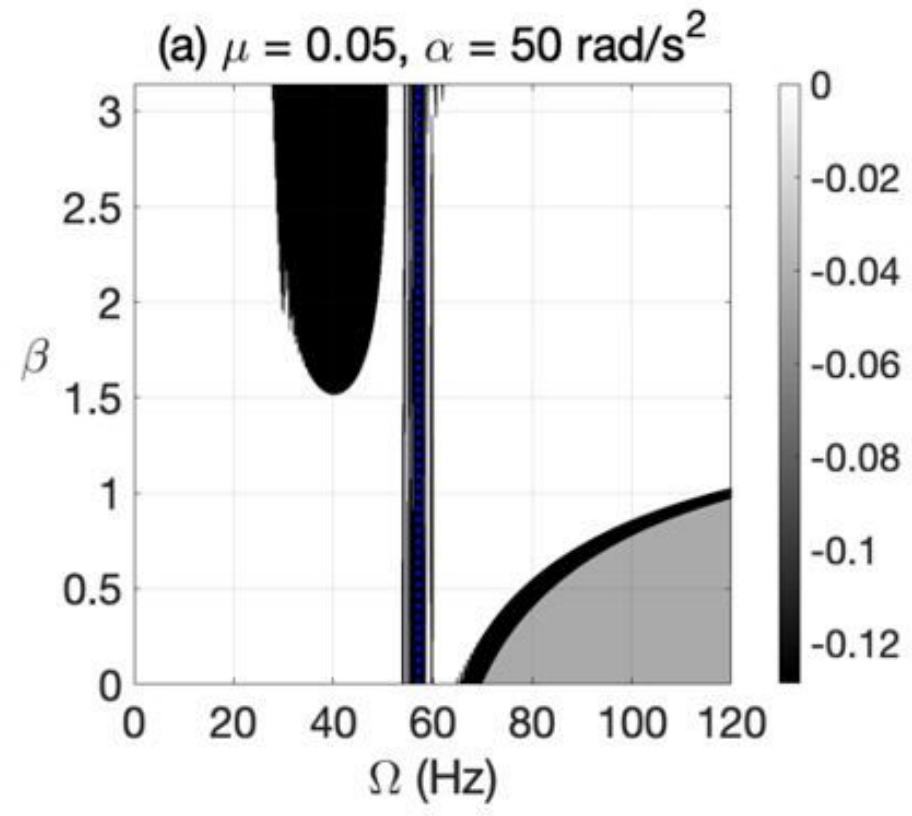

(b) $\mu=0.1, \alpha=50 \mathrm{rad} / \mathrm{s}^{2}$
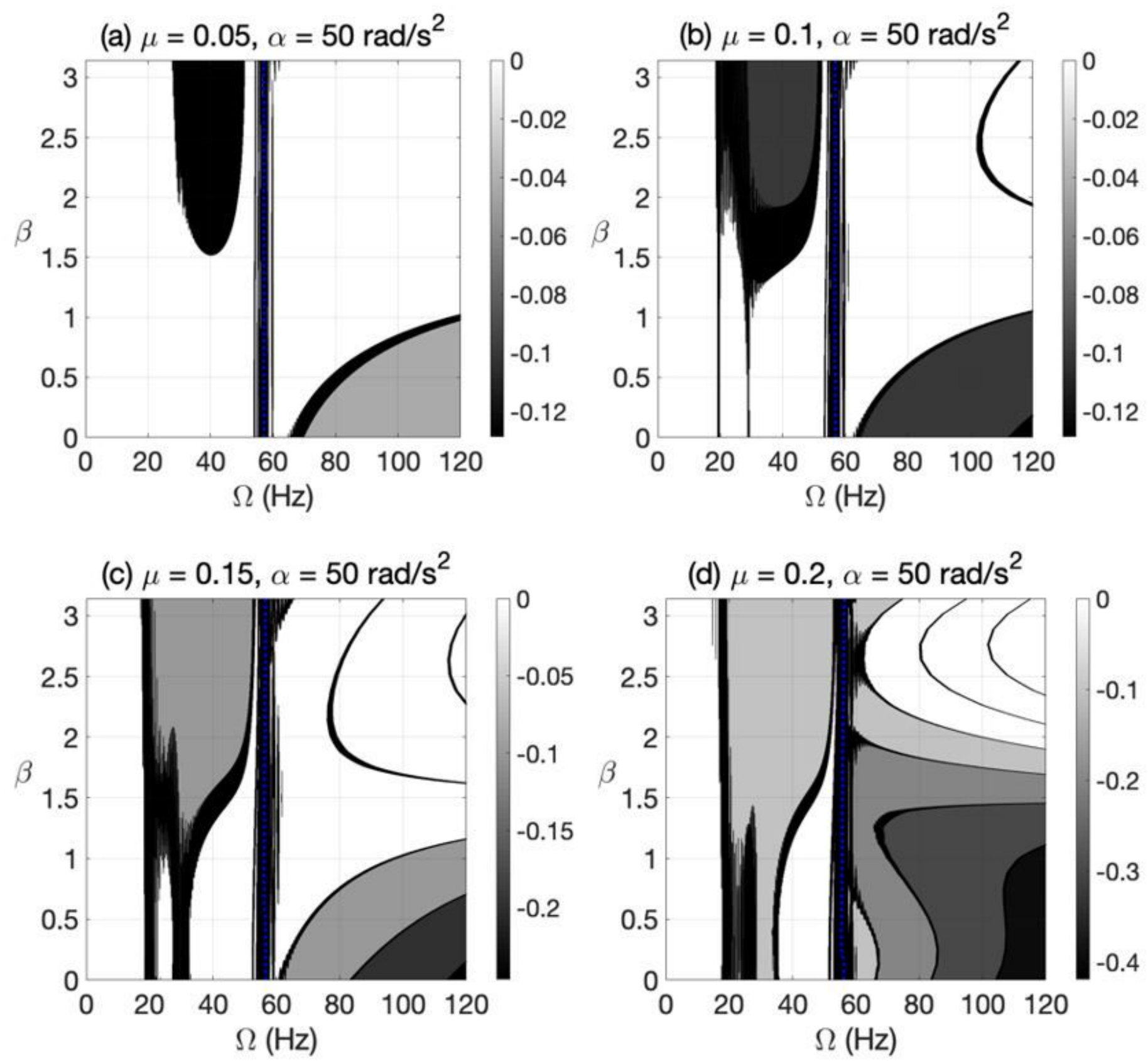

Figure 15

Effect of unbalance force vector angle at varying shaft rotational speeds for on the potential energy content in transient response at breathing crack depths in (a), in (b), in (c) and in (d). 

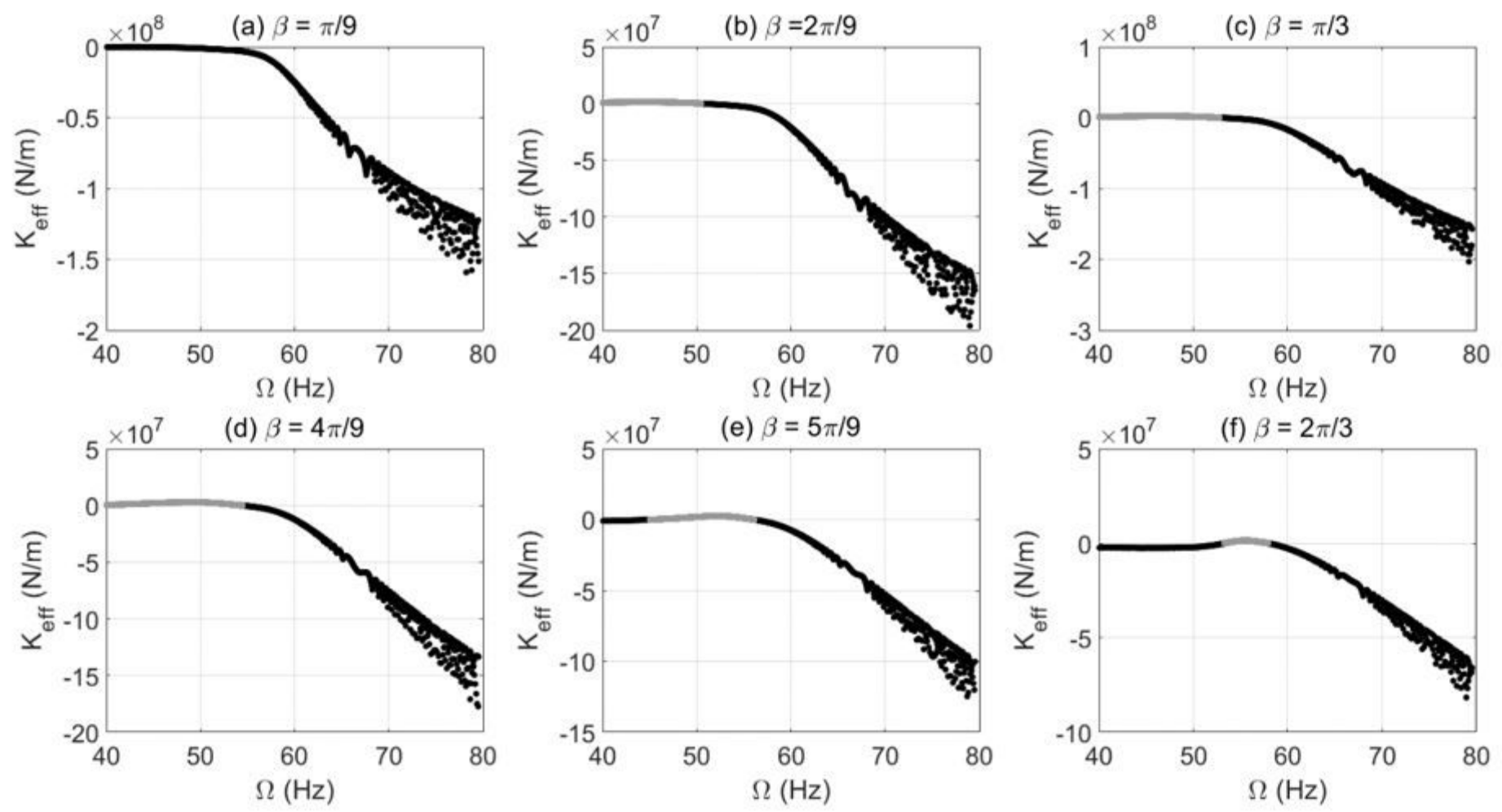

Figure 16

Numerical simulation results in transient response of effective stiffness content at different unbalance force angles and varying shaft rotational speeds for and (gray color: )
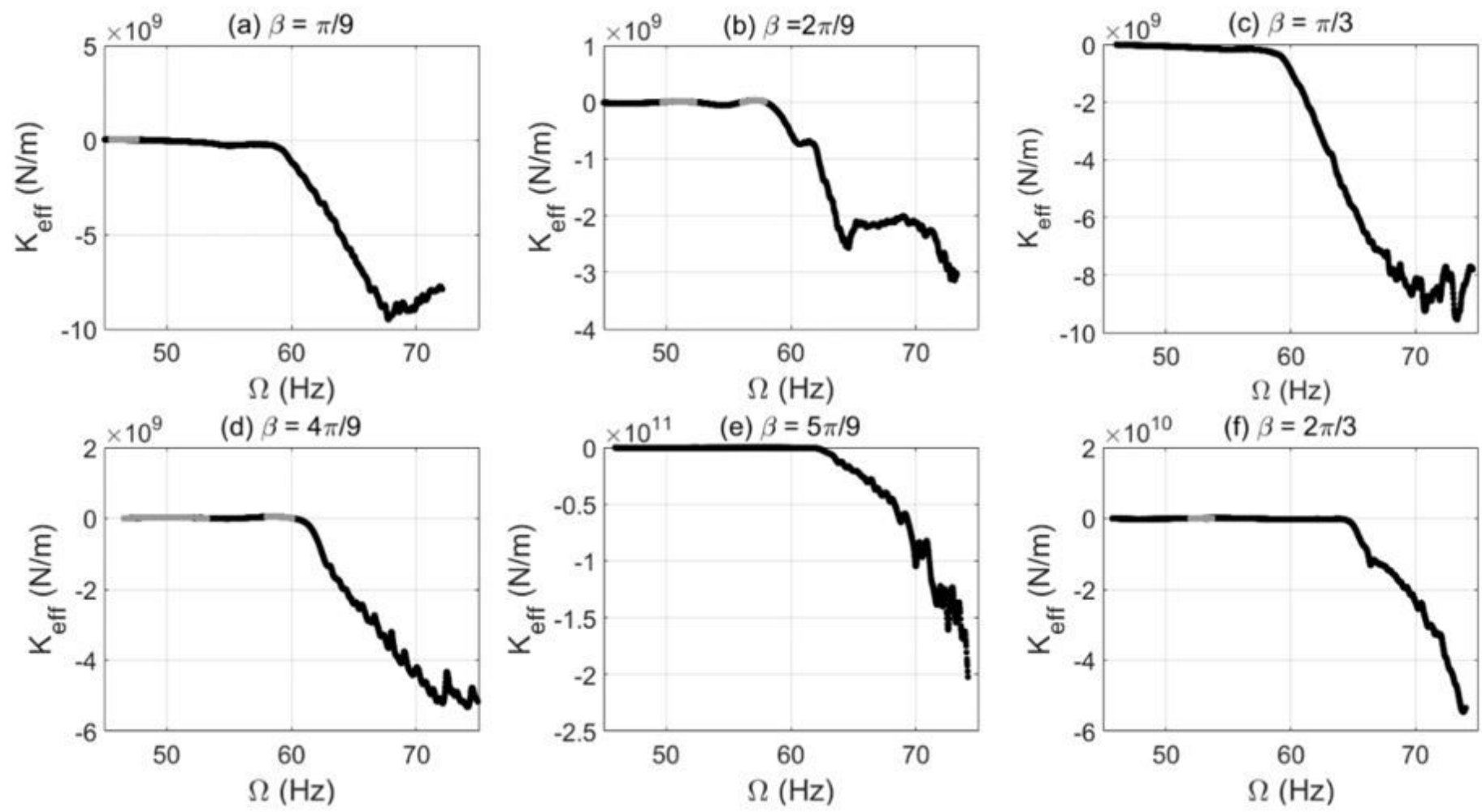

Figure 17 
Experimental results of effective stiffness content in transient response at different unbalance force angles and varying shaft rotational speeds for and (gray color: ) 